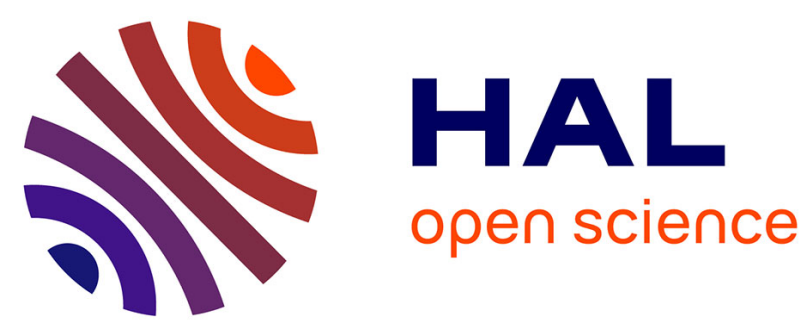

\title{
Addressing various challenges related to food bolus and nutrition with the AM2 mastication simulator
}

Marie-Agnès Peyron, Veronique Sante-Lhoutellier, Dominique Dardevet, M. Hennequin, Didier Remond, François Olivier, A. Woda

\section{To cite this version:}

Marie-Agnès Peyron, Veronique Sante-Lhoutellier, Dominique Dardevet, M. Hennequin, Didier Remond, et al.. Addressing various challenges related to food bolus and nutrition with the AM2 mastication simulator. Food Hydrocolloids, 2019, 97, pp.105229. 10.1016/j.foodhyd.2019.105229 . hal02318545

\section{HAL Id: hal-02318545 \\ https://hal.science/hal-02318545}

Submitted on 25 Oct 2021

HAL is a multi-disciplinary open access archive for the deposit and dissemination of scientific research documents, whether they are published or not. The documents may come from teaching and research institutions in France or abroad, or from public or private research centers.
L'archive ouverte pluridisciplinaire HAL, est destinée au dépôt et à la diffusion de documents scientifiques de niveau recherche, publiés ou non, émanant des établissements d'enseignement et de recherche français ou étrangers, des laboratoires publics ou privés.

\section{(ㄷ)(1) $\$$}

Distributed under a Creative Commons Attribution - NonCommerciall 4.0 International 
4 M.-A. Peyron ${ }^{\mathrm{a}}$, V. Santé-Lhoutellier ${ }^{\mathrm{b}}$, D. Dardevet ${ }^{\mathrm{a}}$, M. Hennequin ${ }^{\mathrm{c}, \mathrm{d}}$, D. Rémond ${ }^{\mathrm{a}}$, O. 5 François $^{\mathrm{c}}$, A. Woda ${ }^{\mathrm{c}}$

6

7 a Université Clermont Auvergne, INRA, UNH, Unité de Nutrition Humaine, CRNH

8 Auvergne, F-63000 Clermont-Ferrand, France

$9 \quad{ }^{b}$ INRA, QuaPA, UR370, F-63122 Saint Genès Champanelle, France

${ }^{\mathrm{c}}$ Université Clermont Auvergne, CROC, F-63000 Clermont-Ferrand, France

${ }^{\mathrm{d}}$ CHU Clermont-Ferrand, Service Odontologie, F-63003 Clermont-Ferrand, France

Corresponding author:

Marie-Agnès PEYRON

INRA, Human Nutrition Unit, Theix

63122 Saint Genès Champanelle

17 France

18 Phone (+33) 473624205

marie-agnes.peyron@inra.fr 


\section{Abstract}

Preparing a food bolus for swallowing is the first and major goal of oral processing ensured by mastication. To fulfill this goal, mastication is accurrately adjusted to the structure and texture of the food. Since the bolus is the main outcome of food oral processing, there is growing interest in improving understanding the food bolus and its features at the end of the masticatory sequence and throughout its formation. Although this step is trivial, its execution is somewhat more complex than it appears. Until now, the food bolus produced has not subjected to full analysis, mainly due to the lack of accessibility during in vivo oral processing.

To overcome this difficulty, we developed a masticator apparatus, named $\mathrm{AM}^{2}$, on the basis of in vivo compression and shear stresses applied on food during oral processing. The apparatus was validated against particle size analyses of boluses produced by individuals presenting normal mastication. The present paper provides a comprehensive overview of the various potential uses of the $\mathrm{AM}^{2}$ apparatus to produce food boluses for a large range of scientific needs.

The food bolus contains much valuable information regarding the progress of mastication, the completion of the function and its role in food disruption, the oral release of food compounds, changes and bioaccessibility, and finally its impact on nutrition. The $\mathrm{AM}^{2}$ apparatus can also be used to simulate mastication in specific populations, such as the elderly and children, and to address various objectives related to this initial step of digestion.

\section{Keywords}

artificial mastication, food bolus, oral release, oral bioaccessibility, oral digestion, nutrition 
Highlights

- The mastication simulator provides food bolus for many foods and various purposes.

- Food disruption, the oral release of food compounds, and digestion can be analyzed.

- Food bolus analysis provides pertinent knowledge on deficient mastication.

- $\mathrm{AM}^{2}$ reveals in vitro bolus features (dynamics, formation) in various oral conditions.

- $\mathrm{AM}^{2}$ is a very attractive model for mechanistic digestion/nutrition studies.

\section{Introduction}

Food oral processing and more specifically the ready-to-swallow food bolus have become major topics of interest in food and dental science (Engelen, Fontijn-Tekamp, \& Bilt, 2005) and in the field of nutrition (Bonnet, Batisse, Peyron, Nicolas, \& Hennequin, 2018; Chen, 2009, 2015; Engelen, Fontijn-Tekamp, \& Bilt, 2005; Ng et al., 2017). Food bolus analysis is at the crossroads between food structure (Gao, Wong, Lim, Henry, \& Zhou, 2015), food formulation, the oral perception of food, food oral processing (Hwang et al., 2012; JalabertMalbos, Mishellany-Dutour, Woda, \& Peyron, 2007; Koç et al., 2014; Shiozawa, Kohyama, \& Yanagisawa, 2003) and the further stages of digestion (Hoebler, Devaux, Karinthi, Belleville, \& Barry, 2000; Hoebler et al., 1998), including oral digestion and related nutrient bioaccessibility (Ellis et al., 2004; Grundy et al., 2015). However, the mere fact that food bolus formation occurs inside the mouth and that access inside the mouth is not possible during mastication hampers most study designs. Collecting the ready-to-swallow bolus in normal or deficient subjects is not a simple procedure. Among other reasons, the bolus is 
often partly swallowed before the final swallow event (Hiiemae et al., 1996), the bolus itself is mixed in an unknown proportion with saliva, making it impossible to determine the proportion of saliva, food fluids and solid nutrients present within the bolus during the masticatory process. During chewing, several physico-chemical processes are at work, transforming the characteristics of the final bolus in an uncontrolled way. In addition, asking volunteers to masticate is sometimes impossible for several reasons such as the use of "experimental" or non-natural food, the presence of food contaminants, the chewers studied are disabled, young children or elderly people, or simply because it is too time consuming. Therefore, in vitro mastication using a mastication simulator is a valuable alternative to an in vivo approach for the experimental production and analysis of food boluses. This kind of simulator also provides solutions for multiple analyzes of food bolus properties at the time of swallowing or of the kinetics involved during its formation, and it provides a more realistic oral simulation than that frequently dene performed before (Funami, 2016; Hedrén, Diaz, \& Svanberg, 2002; Hoebler et al., 2002; Minekus et al., 2014). The possible questions of interest include saliva impregnation, the oral release of nutrients and oral digestion assessment, investigations on the impact of food formulation on the food bolus and its characteristics, for example, in the design of new foods for targeted populations (the elderly, children, noncooperative human subjects, and even animals). It can also be used to examine the oral release of nutrients and of active, toxic substances and food contaminants from the matrix being chewed, for example, to evaluate the role of the oral cavity in the balance between the oral bioaccessibility and bioavailability of nutrients. Using a mastication simulator is also very useful for the production of specific food boluses to address the fate of the food in the digestive tract. Numerous studies are conducted with a simulated bolus produced by mincing, mixing or crushing a food sample without any control of particle size distribution and saliva action in the pre-swallow food bolus before its subjection to artificial digestion (Bornhorst \& 
Singh, 2013; Mandalari et al., 2018; Minekus et al., 2014). A food bolus produced by a mastication simulator is more realistic, closer to the material passing through the esophagus and arriving in the stomach, and it can be subjected to artificial, static or dynamic digestion more pertinently. Indeed the oral step of food destructuration by mastication is very often badly simulated in digestion studies and sometimes not considered at all, even when remarkable in vitro digestion models are used (Dupont et al., 2018; Hoebler et al., 2002; Kong \& Singh, 2008b; Minekus et al., 2014; Shani-Levi et al., 2017). Since the $\mathrm{AM}^{2}$ can produce a realistic food bolus, its association with digestion equipment such as the DIDGI® apparatus (Ménard et al., 2014; Sayd, Chambon, \& Santé-Lhoutellier, 2016) makes it possible to assess the role of mastication in the subsequent steps of digestion. From this perspective, studies could be performed on the role of oral microbiota in bolus formation, nutrient release and digestion when mixed with the intestinal microbiota.

As already reviewed, several artificial mastication simulators have been developed but most of them are unable to produce a food bolus for further analysis or use (Morell, Hernando, \& Fiszman, 2014; Peyron \& Woda, 2016). The Artificial Masticatory Advanced Machine $\left(\mathrm{AM}^{2}\right)$ was developed and validated against in vivo data to address multiple issues regarding in-mouth food processing and the resulting food bolus (Woda et al., 2010a). Its purpose was to simulate the result of mastication, i.e. to produce a food bolus with properties similar to those produced by natural mastication, taking into account food oral management as described in the literature (Chen, 2009). The anatomical features of the teeth and mouth were not duplicated. On the contrary, the basic characteristics of jaw movement and other oral parameters at work during chewing were mimicked so that the production of a pre-swallow food bolus with the $\mathrm{AM}^{2}$ obeys natural physiological laws (Lund \& Kolta, 2006; Woda, Foster, Mishellany, \& Peyron, 2006). Consequently, after correctly selecting the programming, the granulometry of the food boluses obtained at different times during the 
chewing process were similar in vitro and in vivo, thus providing the basis for validating the apparatus (Mishellany-Dutour et al., 2011; Woda et al., 2010a). Until now, very few of the results obtained with this tool have been published (Peyron, Santé-Lhoutellier, François, \& Hennequin, 2018). This article presents an overview of several types of original results obtained with the $\mathrm{AM}^{2}$ in the fields of food and nutrition science related to oral processing. The results presented in Fig.12 are the only ones adapted from the paper published previously (Peyron et al., 2018). Other versions of the $\mathrm{AM}^{2}$ masticator apparatus could be produced to demand. Designing modified prototypes is also undoubtedly a realistic goal in view to satisfaying specific needs to answer various potential scientific questions.

\section{The masticator apparatus $\mathbf{A M}^{2}$}

\subsection{Description of the masticatory apparatus $A M^{2}$}

The complete description of the apparatus and its validation were provided in previous papers (Mishellany-Dutour et al., 2011; Woda et al., 2010a). Briefly, this tool is composed of a cylindrical cavity that constitutes a masticatory chamber (Fig. 1). The two ends of the cylindrical chamber are formed by a fixed masticatory disk (=“maxillary disk") on one side, and a mobile masticatory disk (="mandibular disk") on the other, to simulate the dental arch. These masticatory disks have surfaces whose shape differs from human dental anatomy but are similar to the contact surface area at work in human mastication. They are designed to produce the same types of shear and compression stresses as those exerted in vivo. The mobile masticatory disk is moved like a piston by two motors imparting translational and rotational movements like those described during food management in the mouth during mastication. A spring is located behind the fixed maxillary disk. The force generated for food compression 
during mastication depends on the stiffness of the spring which is chosen as a function of food resistance (Mishellany-Dutour et al., 2011; Woda et al., 2010a). The actions of shearing food material, as well as gathering particles and transporting them to the masticatory surface are performed by the rotational movement of the mandibular disk, as the tongue would do. Water or a validated artificial saliva (Roger-Leroi, Mishellany-Dutour, Woda, Marchand, \& Peyron, 2012) can be injected at the beginning and / or by staggered injections during the masticatory sequence.

\subsection{Programming of the masticatory apparatus $A M^{2}$}

Whatever the objective of the study, a common procedure is used for all foods when programming the $\mathrm{AM}^{2}$ masticatory apparatus. It is always based on preliminary in vivo data collected both from subjects presenting the oral conditions selected for the experiment (healthy oral condition, edentate, etc.) and from the granulometric characteristics of the food bolus collected (Jalabert-Malbos et al., 2007; Ngom, Diagne, Aïdara-Tamba, \& Sene, 2007; van der Bilt, Abbink, Mowlana, \& Heath, 1993). The cumulative particle size distribution curves obtained are used for comparing in vivo and in vitro food boluses. The median particle size $\mathrm{d} 50$, extracted from the cumulative curve by extrapolation and projection on the $\mathrm{x}$-axis, and defined as the theoretical sieve size through which $50 \%$ of the bolus mass can pass, is also used for comparisons. To obtain the most efficient programming, comparisons are made after successive adjustments of the $\mathrm{AM}^{2}$ parameters until the in vivo and in vitro curves and d50 values match each other.

The adjustments made to the mechanical parameters can be of many types and depend on the food masticated.. Briefly, the range of forces to be applied will depend on the spring chosen according its stiffness (from 10.38 to $35.2 \mathrm{~N} / \mathrm{mm}$ ). As examples derived from 
experimental tests, the mastication of a French baguette sample would be done with the 10.38 $\mathrm{N} / \mathrm{mm}$ spring and a raw carrot sample with the $25 \mathrm{~N} / \mathrm{mm}$ spring. The number of masticatory cycles is always obtained from the in vivo measurements of mastication of the food considerd. A large angle (around $200^{\circ}$ ) is chosen for a "fibrous" food, such as meat needing more shear stress to be disrupted compared to a brittle food such as cookies for which an angle of $90^{\circ}$ is enough. Various rotational angles are also tested for gathering particles. The temperature of the masticatory chamber can be regulated at $36^{\circ} \mathrm{C}$ if the oral processing studied is temperature dependent. Water, human or artificial saliva can be used for mastication. The flow and composition of artificial saliva with respect to mucin and enzyme contents (amylase and lipase, for example) can be chosen according to the scientific issue to be addressed (Roger-Leroi et al., 2012). Fig. 2 shows an example of the programming approach in which two numbers of masticatory cycles and two levels of spring-induced forces were sequentially changed in the programming of the masticator apparatus to find the best fit with the in vivo particle size distribution curve in meat bolus analyzed at swallowing time. As shown in Fig. 2, by performing the same number of masticatory cycles as observed in vivo, the stiff spring $(23.5 \mathrm{~N} / \mathrm{mm})$ overly-disrupted the meat bolus compared to the softer spring (18.2 N/mm). Finally, after progressive adjustment, the mean particle size distribution curves of the meat boluses obtained in vivo and in vitro in the conditions selected were identical at swallowing time (Fig. 2).

Similar in vivo - in vitro agreements have also been reported for pork meat and green olive (Peyron \& Woda, 2016). Several examples are shown in Fig. 3 for gherkins, a mouthful of beef, minced beef, Frankfurt sausages, coconut and a pasta product. In vivo - in vitro agreements were also observed when mastication was interrupted at different times while chewing carrots or peanuts (Mishellany-Dutour et al., 2011a) and with pork meat in Fig. 4 (A and B). Fig. 4c shows that the difference observed in the particle size distributions, as well as 
in d50 values, between two types of bread in vivo can be completely reproduced in vitro.

A complete validation of the apparatus should also be performed by considering other physical properties of the food bolus, for example, using an instrumental Texture Profile Analysis (TPA) test consisting in applying double compression on the food bolus. Despite its empirical nature, this test is useful to compare the properties of food boluses collected at different times of the masticatory sequence, for different food matrixes or in different oral conditions, both for in vivo or in vitro food boluses (Peyron et al., 2011). Hardness, recoverability, adhesiveness and springiness values can be extracted from each TPA curve for bolus mechanical characterization. As an example of this interesting use, Fig. 5A illustrates that a piece of French bread (baguette) is softened, rendered less elastic and less cohesive as the in vivo masticatory sequence progresses. Physical characteristics obtained for in vivo and in vitro boluses can be compared to attest the effectiveness of the masticator apparatus (Fig. $5 \mathrm{~B})$. The possible addition of water, or human or artificial saliva in the $\mathrm{AM}^{2}$ is undoubtedely a key parameter in preparing a food bolus for instrumental measurements since it provides the specific rheological environment of the food after mastication. A comparison of the physical characteristics of the in vitro food boluses obtained with these different fluids would be informative regarding the role of the specific components such as enzymes and proteins. Nevertheless, great care must be taken in the treatment of TPA test variables which are not absolute values, they are often misinterpreted, and they can only be used in a comparative way (Nishinari \& Fang, 2018).

All the in vivo data used to validate or to program the masticator apparatus were obtained after collecting the informed consent of each subject and experiments were performed in accordance with different local and national ethical agreements (CE-CIC-GREN-10/06\#5044; DREAM-2013-A00096-39). 


\section{Substance release in the mouth}

Chewing a solid matrix causes the release of numerous substances within the mouth, normally resulting in a satisfactory sensory experience from food containing juice or tasty molecules, for example. It can also favor nutrient extraction as early as the oral step. Conversely, such release must be avoided when the foods or the non-nutritive products contain toxic or pollutant substances as can happen, for example, when a child is chewing or gnawing something containing a non-edible or toxic substance. However, obtaining the delivery of an active substance could be the objective pursued, for example, with medicated chewing-gums (Konar, Palabiyik, Toker, \& Sagdic, 2016).

An artificial device is mandatory when the precise concentration of a compound released during mastication has to be determined. Fig. 6A shows the release curve along the mastication of a non-alimentary product containing two different concentrations of a toxic substance. The kinetics and level of release could be determined and used for toxicity risk analysis. This approach is obviously applicable for quantifying the release of toxic or contaminant compounds from any alimentary product.

Most often the substances analyzed released from food or from any non-nutritive product during chewing are dissolved or dispersed in an oral liquid composed of a mix of saliva and liquids expressed in the food matrix. Determining the true oral concentration of the substance of interest implies the separation of these two types of liquids. In usual conditions, the volume of saliva cannot be determined because the saliva flow undergoes a large number of unpredictable variations and due to frequent intermediate swallows (Hiiemae \& Palmer, 1999). $\mathrm{AM}^{2}$ can be used to distinguish between saliva and the juice extracted from food.

In the examples shown in Fig. 6 (B and $\mathrm{C}$ ), mango juice was collected in vivo after chewing with the fruit placed within an impermeable plastic bag (Fig. 6B) and in vitro with 
251 the fruit in the $\mathrm{AM}^{2}$ (Fig. 6C). The weight of the mango juice collected in vitro after 24

252 masticatory cycles was similar to the amount obtained after in vivo chewing performed with

25324 cycles. With this $\mathrm{AM}^{2}$ based design, the juice released from the matrix disruption was

254 estimated to be about $20 \%$ of the initial weight of the mango sample (Fig. 6Bb). Without the

255 bag, the in vivo mastication produced a liquid phase composed of juice and saliva,

256 representing about $40 \%$ of the bolus weight. As expected, the amount of mango juice

257 extracted also depended on the number of chewing cycles (Fig. 6C).

Fig. 7 shows the kinetics of glucose release in saliva during in vivo and in vitro mastication

of a chewing gum. In this experiment, the gum was weighed before and after 1, 3, 6, 10 and

12 min chewing. The gum weight was expressed as the cumulative course of weight loss observed along the masticatory sequences (Fig. 7A). The glucose was determined in saliva samples at the same time points of the masticatory sequence (Fig. 7B). It was obtained with a glucometer using the electrochemical determination of glucose oxidase activity compared to the pre-established standard curve for glucose in saliva. The results were expressed as the cumulative time course of the amount of glucose measured in saliva at the different time points of the masticatory sequences. Mastication occurred either in vivo with 8 food bolus samples obtained from five volunteers or in vitro with 8 repetitions performed with the masticator apparatus. The greater proportion of glucose release occurred during the three first minutes of mastication and the gum weight decreased mostly at the same time. Weight loss and glucose release changes had similar time courses for in vivo and in vitro gum chewing.

This kind of experiment can be conducted, for example, for the development of a medicated chewing gum designed to provide a slow steady release of the medicine contained in it, favoring the release of a substance in saliva and its progressive absorption. A relevant time-curve would be obtained with the $\mathrm{AM}^{2}$ apparatus. 


\section{Oral bioaccessibility of nutrients, digestion studies}

The role of mastication and considerable food matrix disruption in the absorption of nutrients is important (Pennings et al., 2013; Rémond et al., 2007). Sieving through a tissue mesh enables the separate collection of liquid and solid phases of the food bolus, giving access to the role of oral processes in nutrient bioaccessibility and digestion. This method has been successfully applied in in vitro food boluses. Fig. 8 (ABC) shows free-iron release from the a meat matrix during the mastication of either a beef sample or its minced counterpart. Although the bolus of minced meat was normally chewed in fewer masticatory cycles than the same meat not minced (10 versus 32 cycles), it produced a bolus composed of more small particles (Fig. 8A). Free-iron release from the matrix (Fig. 8B and C) rose significantly in both saliva and bolus material when the meat had been minced before mastication (12 replicates for iron determination). Fig. 8D shows that the amount of $\beta$-carotenes released in saliva during the in vivo mastication of raw carrot increased along the masticatory process, obviously due to matrix disruption. This kind of measurement is totally feasible in vitro with the masticatory simulator. The analysis of the bioaccessibility of carotenoids could undoubtedly be performed in vitro with the $\mathrm{AM}^{2}$, since the release of nutrients from plant foods is largely dependent on food breakage during mastication and could be decisive for their bioavailability (Faulks \& Southon, 2005; Hedrén et al., 2002; Palafox-Carlos, AyalaZavala, \& González-Aguilar, 2011). Oral bioaccessibility is also a relevant issue for other macro and micronutrients such as in the case of lipids in almonds (Cassady, Hollis, Fulford, Considine, \& Mattes, 2009; Ellis et al., 2004; Grundy et al., 2015).

Fig. 9 illustrates the first step of digestion occurring in the mouth during mastication and quantified by the production of maltose after the oral hydrolysis of starch by salivary amylase.

Pieces of different breads $(2.5 \mathrm{~g})$ were introduced in the $\mathrm{AM}^{2}$. Mastication was carried out (20 
masticatory cycles) either with water (Volvic $®)$ or human saliva (1.6 mL as estimated by weighting in vivo food boluses collected during the programming of the $\mathrm{AM}^{2}$ apparatus). Logically, as expected, the concentration of maltose was higher with human saliva than with water, but also differed regarding the type of bread chewed. The mastication of pieces of white bread led to significantly higher hydrolysis of maltose than the mastication of whole wheat bread of the same weight. This observation confirmed the initiatory role of mastication in digestion by disintegrating food into smaller particles that are impregnated by saliva (Hoebler et al., 1998; Pentikäinen et al., 2019; Tournier, Grass, Zope, Salles, \& Bertrand, 2012).

Although the major mechanical reduction of food occurs during mastication, it is completed in the stomach (Kong \& Singh, 2011). This continuum of activity is exemplified in Fig. 10a, which shows the granulometric characteristics measured first in the in vitro food bolus of pasta obtained with the $\mathrm{AM}^{2}$ just before swallowing, and then in the gastric compartment after in vitro digestion. Moreover, this example also highlighted that the stomach cannot totally overcome the failure in food reduction during deficient mastication resulting in a bolus with numerous large particles. This must be taken into account, considering that the level of disintegration of a food in the stomach depends on the structure of the matrix (Kong \& Singh, 2008a) and impacts gastric emptying (Pera et al., 2002), thus assigning a specific role to mastication and the quality of the food bolus arriving in the stomach. Large particles have also been shown to lengthen gastric emptying and to produce lower glycemic and insulin blood responses than smaller particles (Ranawana, Clegg, Shafat, \& Henry, 2011). This could be an acceptable explanation for the lengthening of the whole digestive process and the delay in nutrient postprandial appearance observed in edentulous people (Rémond et al., 2007).

Fig. 10B shows the kinetics of protein concentration measured in vitro in the stomach 
simulating digestion of an elderly person (in terms of $\mathrm{pH}$ kinetics and pepsin amount) after the oral ingestion of meat. Using the masticator apparatus $\mathrm{AM}^{2}$ with different programmings to simulate either in vitro normal or deficient mastication, combined with an instrumental gastric system, it appeared that large food fragments constituting the food bolus after deficient in vitro mastication resulted in a significant deficit in protein release in elderly digestive conditions.

\section{Biochemical modifications during oral processing}

$$
\text { The mastication simulator offers the possibility of exploring the chemical role of saliva and }
$$
modification of the food compounds occurring within the mouth while the food is being transformed into a bolus ready to be swallowed. The various roles of saliva can be explored since it can be added or not in the apparatus for in vitro mastication. For example, human saliva is assumed to protect food compounds against oxidation (Moore, Calder, Miller, \& Rice-Evans, 1994). Thus the $\mathrm{AM}^{2}$ allows testing the role of saliva by using in vitro no-saliva, human saliva or any composition of artificial saliva containing enzymes or not, for example. Fig. 11 (A and B) shows the effect of chewing on the oxidation of beef meat when the artificial mouth was devoid of saliva. Lipid and protein oxidation in the food bolus was assessed by changes in TBARS (ThioBarbituric Acid Reactive Substances) and by the quantification of carbonyl groups (aldehydes and ketones), respectively. Three meat samples were measured before chewing (raw meat, cooked meat, cooked + minced meat) and 12 boluses were obtained after in vitro mastication (just before swallowing). Without saliva, significantly higher lipid oxidation was observed when the meat sample was chewed in minced format rather than as a non-minced meat (Fig. 11A). The oxidation of proteins occurring during chewing without saliva was also significant although less marked than for 
351 lipids (Fig. 11B). These results confirm the potential occurrence of lipid and protein oxidation

352 and underline the essential antioxidant role of saliva in protecting food compounds from

353 oxidation (Qu et al., 2016). The more a food is chewed the more likely it will be impregnated

354 by saliva and the nutrients protected against oxidation. This aspect should be thoroughly

355 studied for various foods since it may have serious consequences for certain nutritional issues

356 as nutrient oxidation has known consequences on intestinal absorption (Bax et al., 2012).

\section{Effect of deficient mastication on food bolus processing}

The $\mathrm{AM}^{2}$ can also simulate different dental states related to oral diseases, healthy childhood and ageing conditions. Fig. 12 indicates the effects of different modalities of impairment on the granulometry of poultry meatball boluses (Peyron et al., 2018). The in vivo boluses were collected from seven subjects at swallowing threshold after normal mastication (NM) composed of 17 masticatory cycles. As usual, preliminary in vivo experiments allowed determining the main settings for in vitro mastication, and the simulation of deficient mastication was performed with modifications of certain parameters. This introduced specific deteriorations of the masticatory sequence in terms of the force and motility of oral elements, as illustrated in Figure 2 for the choice of spring-induced forces. Two levels were set for deficient force by using the spring of lowest stiffness together with an increasing offset between the jaws at closing (Def Force 1 and Def Force 2) and deficient motility simulated by

371 two different low values of rotation angle (compared to normal programming) applied during 372 jaw confrontation (Def Motil 1 and Def Motil 2). A considerable decline in masticatory force 373 (Def Force 2 in Fig. 12) significantly changed the particle size distribution in the meatball 374 boluses towards a greater proportion of large particles $(\mathrm{p}<0.001)$. Motility deficiency also significantly limited food fragmentation, with an impact corresponding to the level of the 
deficiency $(\mathrm{p}<0.001)$. This difference was even more dramatic when the masticatory force and motility deficiencies (Def Motil \& Force) were added together during mastication compared to other conditions $(\mathrm{p}<0.001)$. The description of the impact of gradual and cumulative deficiencies on the physical properties of boluses obtained with poultry meatballs has been described elsewhere (Peyron et al., 2018) and the results agreed with those obtained in vivo (Mishellany-Dutour, Renaud, Peyron, Rimek, \& Woda, 2008; Woda et al., 2010b).

\section{Measurement of forces applied during mastication}

The $\mathrm{AM}^{2}$ can measure forces developed during mastication with a strength sensor (Fig. 1). The specific approach described in Figs. 13 and 14 is mandatory. The large artifacts recorded from the force sensor included in the $\mathrm{AM}^{2}$ came from frictions induced by the mobile jaw's forward and backward movements. This implied stopping all the movements for one or two seconds during which the force was measured. Fig. 13A shows the method used to calibrate the force sensor to a null force with an empty mastication chamber to overcome the artifacts. Fig. 13B shows an experiment on force measurements performed with gelatin samples as models (10 $\mathrm{mm}$ high, $20 \mathrm{~mm}$ diameter) presenting three levels of hardness but the same recoverability_(Peyron, Lassauzay, \& Woda, 2002). The forces recorded during five successive cycles differed according to the level of hardness of the food models.

Fig. 14A shows an experiment where the forces used during a long sequence of 36 cycles were recorded during the chewing sequence of a banana sample $(10 \mathrm{~mm}$ high and $20 \mathrm{~mm}$ diameter). During this experiment the moving jaw compressed the sample, while the fixed jaw moved back due to spring compression, leading to a partial deformation of the sample. The masticatory forces progressively decreased from $25.42 \pm 0.81 \mathrm{~N}$-at the first bite to near zero $\mathrm{N}$ at the last bite (5 replicates). A comparable force value $(26.99 \pm 1.08 \mathrm{~N})$ was measured 
401

402

403

404

405

406

407

408

409

410

411

412

413

414

415

416

417

418

419

420

421

422

423

424

425

with the Instron machine (Fig. 14B) performing a single compression test at $65 \%$ deformation (the same deformation range applied on the banana sample by the $\mathrm{AM}^{2}$ ) on two banana samples taken from the same bunch as the sample used for the experiment presented in Fig. 14A. The resistance force obtained with the Instron machine when the sample was compressed $(26.99 \pm 1.08 \mathrm{~N})$ was comparable to that obtained with the $\mathrm{AM}^{2}$ at the first bite. In another experiment presented in Fig. 14 (C and D), the $\mathrm{AM}^{2}$ was used to mimick testing machine mode to test the effect of fruit ripening. The ripe and firm banana samples were subjected to five successive compressions. The resistance was higher $(7.93 \pm 1.22 \mathrm{~N})$ for the firm banana than for the ripe one $(4.28 \pm 1.04 \mathrm{~N})$.

\section{Conclusion}

For various reasons ranging from financial to ethical considerations, but also because it is not possible to access the interior of the mouth during mastication, the $\mathrm{AM}^{2}$ masticator apparatus offers a unique approach in numerous fields of research in food science, including food design, oral health and nutrition issues. It facilitates experiments in particular when large samples of subjects or high numbers of replicates would be required in vivo. Also, the number of repetitions can be much smaller because the variations between them are due only to mechanical hazards that are much easier to control than biological intersubject variations. Finally, no ethical requirements are needed with in vitro experiments.

The $\mathrm{AM}^{2}$ has certain limits. Contrary to many other articial masticators (Salles et al., 2007; van Ruth \& Buhr, 2004), it does not currently offer the possibility of collecting volatile aromatic compounds during food disruption within the masticatory chamber. This limit, however, could be overcome technically if needed. At present, the choice of masticatory programming is based on several in vivo recordings followed by the adjustment of the $\mathrm{AM}^{2}$ 
parameters- In the future, it may be possible to introduce a retrocontrol based on neural networks in the $\mathrm{AM}^{2}$ which would allow adaptation to ongoing food bolus transformation, as is the case in in vivo mastication

Funding: This work was supported by the European Community [FP7-222 654-DREAM]; the "Qualiment" French Carnot Institute [Qualigras-Phy, AAP 2012]; and the French National Research Agency [AlimaSSenS - ANR-14-CE20-0003-01]. The $\mathrm{AM}^{2}$ has been developped with the support of the Auvergne Region (Bourse Innovation), the Université d'Auvergne and the French National Institute for Agricultural Research (INRA), and is a platform of the Université Clermont Auvergne (UCA-PARTNER).

Declarations of interest: none

\section{References}

Bax, M.-L., Aubry, L., Ferreira, C., Daudin, J.-D., Gatellier, P., Rémond, D., \& SantéLhoutellier, V. (2012). Cooking temperature is a key determinant of in vitro meat protein digestion rate: investigation of underlying mechanisms. Journal of Agricultural and Food Chemistry, 60(10), 2569-2576. https://doi.org/10.1021/jf205280y

Bonnet, G., Batisse, C., Peyron, M.-A., Nicolas, E., \& Hennequin, M. (2018). Which variables should be controlled when measuring the granulometry of a chewed bolus? A systematic review. Journal of Texture Studies. https://doi.org/10.1111/jtxs.12376

Bornhorst, G. M., \& Singh, R. P. (2013). Kinetics of in Vitro Bread Bolus Digestion with Varying Oral and Gastric Digestion Parameters. Food Biophysics, 8(1), 50-59. https://doi.org/10.1007/s11483-013-9283-6 
451 Cassady, B. A., Hollis, J. H., Fulford, A. D., Considine, R. V., \& Mattes, R. D. (2009).

452

453

454

455

456

457

458

459

460

461

462

463

464

465

466

467

468

469

470

471

472

473

474

475 Mastication of almonds: effects of lipid bioaccessibility, appetite, and hormone response. The American Journal of Clinical Nutrition, 89(3), 794-800. https://doi.org/10.3945/ajcn.2008.26669

Chen, J. (2009). Food oral processing-A review. Food Hydrocolloids, 23(1), 1-25. https://doi.org/10.1016/j.foodhyd.2007.11.013

Chen, J. (2015). Food oral processing: Mechanisms and implications of food oral destruction. Trends in Food Science \& Technology, 45(2), 222-228. https://doi.org/10.1016/j.tifs.2015.06.012

Dupont, D., Alric, M., Blanquet-Diot, S., Bornhorst, G., Cueva, C., Deglaire, A., ... Van den Abbeele, P. (2018). Can dynamic in vitro digestion systems mimic the physiological reality? Critical Reviews in Food Science and Nutrition, 1-17. https://doi.org/10.1080/10408398.2017.1421900

Ellis, P. R., Kendall, C. W. C., Ren, Y., Parker, C., Pacy, J. F., Waldron, K. W., \& Jenkins, D. J. A. (2004). Role of cell walls in the bioaccessibility of lipids in almond seeds. The American Journal of Clinical Nutrition, 80(3), 604-613. https://doi.org/10.1093/ajcn/80.3.604

Engelen, L., Fontijn-Tekamp, A., \& Bilt, A. van der. (2005). The influence of product and oral characteristics on swallowing. Archives of Oral Biology, 50(8), 739-746. https://doi.org/10.1016/j.archoralbio.2005.01.004

Faulks, R. M., \& Southon, S. (2005). Challenges to understanding and measuring carotenoid bioavailability. Biochimica Et Biophysica Acta, 1740(2), 95-100. https://doi.org/10.1016/j.bbadis.2004.11.012

Funami, T. (2016). The Formulation Design of Elderly Special Diets: Formulation design for elderly. Journal of Texture Studies, 47(4), 313-322. https://doi.org/10.1111/jtxs.12202 
Gao, J., Wong, J. X., Lim, J. C.-S., Henry, J., \& Zhou, W. (2015). Influence of bread structure on human oral processing. Journal of Food Engineering, 167, 147-155. https://doi.org/10.1016/j.jfoodeng.2015.07.022

Grundy, M. M. L., Grassby, T., Mandalari, G., Waldron, K. W., Butterworth, P. J., Berry, S. E. E., \& Ellis, P. R. (2015). Effect of mastication on lipid bioaccessibility of almonds in a randomized human study and its implications for digestion kinetics, metabolizable energy, and postprandial lipemia. The American Journal of Clinical Nutrition, 101(1), 25-33. https://doi.org/10.3945/ajcn.114.088328

Hedrén, E., Diaz, V., \& Svanberg, U. (2002). Estimation of carotenoid accessibility from carrots determined by an in vitro digestion method. European Journal of Clinical Nutrition, 56(5), 425-430. https://doi.org/10.1038/sj.ejcn.1601329

Hiiemae, K., Heath, M. R., Heath, G., Kazazoglu, E., Murray, J., Sapper, D., \& Hamblett, K. (1996). Natural bites, food consistency and feeding behaviour in man. Archives of Oral Biology, 41(2), 175-189.

Hiiemae, K. M., \& Palmer, J. B. (1999). Food transport and bolus formation during complete feeding sequences on foods of different initial consistency. Dysphagia, 14(1), 31-42. https://doi.org/10.1007/PL00009582

Hoebler, C., Devaux, M. F., Karinthi, A., Belleville, C., \& Barry, J. L. (2000). Particle size of solid food after human mastication and in vitro simulation of oral breakdown. International Journal of Food Sciences and Nutrition, 51(5), 353-366.

Hoebler, C., Karinthi, A., Devaux, M.-F., Guillon, F., Gallant, D. J. G., Bouchet, B., ... Barry, J.-L. (1998). Physical and chemical transformations of cereal food during oral digestion in human subjects. British Journal of Nutrition, 80(05), 429. https://doi.org/10.1017/S0007114598001494 
500 Hoebler, C., Lecannu, G., Belleville, C., Devaux, M.-F., Popineau, Y., \& Barry, J.-L. (2002).

501

502

503

504

505

506

507

508

509

510

511

512

513

514

515

516

517

518

519

520

521

522

Development of an in vitro system simulating bucco-gastric digestion to assess the physical and chemical changes of food. International Journal of Food Sciences and Nutrition, 53(5), 389-402. https://doi.org/10.1080/0963748021000044732

Hwang, J., Kim, D.-K., Bae, J. H., Kang, S. H., Seo, K. M., Kim, B. K., \& Lee, S. Y. (2012). The effect of rheological properties of foods on bolus characteristics after mastication. Annals of Rehabilitation $\quad$ Medicine, 36(6), 776-784. https://doi.org/10.5535/arm.2012.36.6.776

Jalabert-Malbos, M.-L., Mishellany-Dutour, A., Woda, A., \& Peyron, M.-A. (2007). Particle size distribution in the food bolus after mastication of natural foods. Food Quality and Preference, 18(5), 803-812. https://doi.org/10.1016/j.foodqual.2007.01.010

Koç, H., Çakir, E., Vinyard, C. J., Essick, G., Daubert, C. R., Drake, M. A., ... Foegeding, E. A. (2014). Adaptation of Oral Processing to the Fracture Properties of Soft Solids: Oral Processing and Fracture Properties. Journal of Texture Studies, 45(1), 47-61. https://doi.org/10.1111/jtxs.12051

Konar, N., Palabiyik, I., Toker, O. S., \& Sagdic, O. (2016). Chewing gum: Production, quality parameters and opportunities for delivering bioactive compounds. Trends in Food Science \& Technology, 55, 29-38. https://doi.org/10.1016/j.tifs.2016.07.003

Kong, F., \& Singh, R. P. (2008). A model stomach system to investigate disintegration kinetics of solid foods during gastric digestion. Journal of Food Science, 73(5), E202210. https://doi.org/10.1111/j.1750-3841.2008.00745.x

Kong, Fanbin, \& Singh, R. P. (2011). Solid Loss of Carrots During Simulated Gastric Digestion. Food Biophysics, 6(1), 84-93. https://doi.org/10.1007/s11483-010-9178-8 
523 Lund, J. P., \& Kolta, A. (2006). Generation of the central masticatory pattern and its modification by sensory feedback. Dysphagia, 21(3), 167-174. https://doi.org/10.1007/s00455-006-9027-6

Mandalari, G., Parker, M. L., Grundy, M. M.-L., Grassby, T., Smeriglio, A., Bisignano, C., ... Wilde, P. J. (2018). Understanding the Effect of Particle Size and Processing on Almond Lipid Bioaccessibility through Microstructural Analysis: From Mastication to Faecal Collection. Nutrients, 10(2). https://doi.org/10.3390/nu10020213

Ménard, O., Cattenoz, T., Guillemin, H., Souchon, I., Deglaire, A., Dupont, D., \& Picque, D. (2014). Validation of a new in vitro dynamic system to simulate infant digestion. Food Chemistry, 145, 1039-1045. https://doi.org/10.1016/j.foodchem.2013.09.036

Minekus, M., Alminger, M., Alvito, P., Ballance, S., Bohn, T., Bourlieu, C., ... Brodkorb, A. (2014). A standardised static in vitro digestion method suitable for food - an international consensus. Food \& Function, 5(6), 1113-1124. https://doi.org/10.1039/c3fo60702j

Mishellany-Dutour, A., Peyron, M.-A., Croze, J., François, O., Hartmann, C., Alric, M., \& Woda, A. (2011a). Comparison of food boluses prepared in vivo and by the AM2 mastication simulator. Food Quality and Preference, 22(4), 326-331. https://doi.org/10.1016/j.foodqual.2010.12.003

Mishellany-Dutour, A., Peyron, M.-A., Croze, J., François, O., Hartmann, C., Alric, M., \& Woda, A. (2011b). Comparison of food boluses prepared in vivo and by the AM2 mastication simulator. Food Quality and Preference, 22(4), 326-331. https://doi.org/10.1016/j.foodqual.2010.12.003

Mishellany-Dutour, A., Renaud, J., Peyron, M.-A., Rimek, F., \& Woda, A. (2008). Is the goal of mastication reached in young dentates, aged dentates and aged denture wearers? The 
British

Journal

of

Nutrition,

99(1),

121-128. https://doi.org/10.1017/S0007114507795284

Moore, S., Calder, K. A., Miller, N. J., \& Rice-Evans, C. A. (1994). Antioxidant activity of saliva and periodontal disease. Free Radical Research, 21(6), 417-425.

Morell, P., Hernando, I., \& Fiszman, S. M. (2014). Understanding the relevance of in-mouth food processing. A review of in vitro techniques. Trends in Food Science \& Technology, 35(1), 18-31. https://doi.org/10.1016/j.tifs.2013.10.005

Ng, G. C. F., Gray-Stuart, E. M., Morgenstern, M. P., Jones, J. R., Grigg, N. P., \& Bronlund, J. E. (2017). The slip extrusion test: A novel method to characterise bolus properties. Journal of Texture Studies, 48(4), 294-301. https://doi.org/10.1111/jtxs.12254

Ngom, P. I., Diagne, F., Aïdara-Tamba, A. W., \& Sene, A. (2007). Relationship between orthodontic anomalies and masticatory function in adults. American Journal of Orthodontics and Dentofacial Orthopedics, 131(2), 216-222. https://doi.org/10.1016/j.ajodo.2005.03.027

Nishinari, K., \& Fang, Y. (2018). Perception and measurement of food texture: Solid foods. Journal of Texture Studies, 49(2), 160-201. https://doi.org/10.1111/jtxs.12327

Palafox-Carlos, H., Ayala-Zavala, J. F., \& González-Aguilar, G. A. (2011). The role of dietary fiber in the bioaccessibility and bioavailability of fruit and vegetable antioxidants. Journal of Food Science, 76(1), R6-R15. https://doi.org/10.1111/j.17503841.2010.01957.x

Pennings, B., Groen, B. B. L., van Dijk, J.-W., de Lange, A., Kiskini, A., Kuklinski, M., ... van Loon, L. J. C. (2013). Minced beef is more rapidly digested and absorbed than beef steak, resulting in greater postprandial protein retention in older men. The American Journal of Clinical Nutrition, 98(1), 121-128. https://doi.org/10.3945/ajcn.112.051201 
571 Pentikäinen, S., Koistinen, V., Kolehmainen, M., Poutanen, K., Hanhineva, K., \& Aura, A.-

572

573

574

575

576

577

578

579

580

581

582

583

584

585

586

587

588

589

590

591

592

593

594

595

M. (2019). Mastication-induced release of compounds from rye and wheat breads to saliva. Food Chemistry, 270, 502-508. https://doi.org/10.1016/j.foodchem.2018.07.110

Pera, P., Bucca, C., Borro, P., Bernocco, C., De, L. A., \& Carossa, S. (2002). Influence of mastication on gastric emptying. Journal of Dental Research, 81(3), 179-181.

Peyron, M. A., Lassauzay, C., \& Woda, A. (2002). Effects of increased hardness on jaw movement and muscle activity during chewing of visco-elastic model foods. Experimental Brain Research, 142(1), 41-51. https://doi.org/10.1007/s00221-001-09165

Peyron, M.-A., Gierczynski, I., Hartmann, C., Loret, C., Dardevet, D., Martin, N., \& Woda, A. (2011). Role of physical bolus properties as sensory inputs in the trigger of swallowing. PloS One, 6(6), e21167. https://doi.org/10.1371/journal.pone.0021167

Peyron, M.-A., Santé-Lhoutellier, V., François, O., \& Hennequin, M. (2018). Oral declines and mastication deficiencies cause alteration of food bolus properties. Food \& Function, 9(2), 1112-1122. https://doi.org/10.1039/c7fo01628j

Peyron, Marie-Agnès, \& Woda, A. (2016). An update about artificial mastication. Current Opinion in Food Science, 9, 21-28. https://doi.org/10.1016/j.cofs.2016.03.006

Qu, X. M., Wu, Z. F., Pang, B. X., Jin, L. Y., Qin, L. Z., \& Wang, S. L. (2016). From Nitrate to Nitric Oxide: The Role of Salivary Glands and Oral Bacteria. Journal of Dental Research, 95(13), 1452-1456. https://doi.org/10.1177/0022034516673019

Ranawana, V., Clegg, M. E., Shafat, A., \& Henry, C. J. (2011). Postmastication digestion factors influence glycemic variability in humans. Nutrition Research (New York, N.Y.), 31(6), 452-459. https://doi.org/10.1016/j.nutres.2011.05.006

Rémond, D., Machebeuf, M., Yven, C., Buffière, C., Mioche, L., Mosoni, L., \& Patureau Mirand, P. (2007). Postprandial whole-body protein metabolism after a meat meal is 

influenced by chewing efficiency in elderly subjects. The American Journal of Clinical Nutrition, 85(5), 1286-1292. https://doi.org/10.1093/ajcn/85.5.1286

Roger-Leroi, V., Mishellany-Dutour, A., Woda, A., Marchand, M., \& Peyron, M. A. (2012). Substantiation of an artificial saliva formulated for use in a masticatory apparatus. Odonto-Stomatologie Tropicale = Tropical Dental Journal, 35(138), 5-14.

Salles, C., Tarrega, A., Mielle, P., Maratray, J., Gorria, P., Liaboeuf, J., \& Liodenot, J.-J. (2007). Development of a chewing simulator for food breakdown and the analysis of in vitro flavor compound release in a mouth environment. Journal of Food Engineering, 82(2), 189-198. https://doi.org/10.1016/j.jfoodeng.2007.02.008

Sayd, T., Chambon, C., \& Santé-Lhoutellier, V. (2016). Quantification of peptides released during in vitro digestion of cooked meat. Food Chemistry, 197 Pt B, 1311-1323. https://doi.org/10.1016/j.foodchem.2015.11.020

Shani-Levi, C., Alvito, P., Andrés, A., Assunção, R., Barberá, R., Blanquet-Diot, S., ... Lesmes, U. (2017). Extending in vitro digestion models to specific human populations: Perspectives, practical tools and bio-relevant information. Trends in Food Science \& Technology, 60, 52-63. https://doi.org/10.1016/j.tifs.2016.10.017

Shiozawa, K., Kohyama, K., \& Yanagisawa, K. (2003). Relationship between Physical Properties of a Food Bolus and Initiation of Swallowing. Japanese Journal of Oral Biology, 45(2), 59-63. https://doi.org/10.2330/joralbiosci1965.45.59

Tournier, C., Grass, M., Zope, D., Salles, C., \& Bertrand, D. (2012). Characterization of bread breakdown during mastication by image texture analysis. Journal of Food Engineering, 113(4), 615-622. https://doi.org/10.1016/j.jfoodeng.2012.07.015

van der Bilt, A., Abbink, J. H., Mowlana, F., \& Heath, M. R. (1993). A comparison between data analysis methods concerning particle size distributions obtained by mastication in 
man. Archives of Oral Biology, 38(2), 163-167. https://doi.org/10.1016/00039969(93)90202-W

van Ruth, S. M., \& Buhr, K. (2004). Influence of mastication rate on dynamic flavour release analysed by combined model mouth/proton transfer reaction-mass spectrometry. International Journal of Mass Spectrometry, 239(2-3), 187-192. https://doi.org/10.1016/j.ijms.2004.08.009

Woda, A., Foster, K., Mishellany, A., \& Peyron, M. A. (2006). Adaptation of healthy mastication to factors pertaining to the individual or to the food. Physiology \& Behavior, 89(1), 28-35. https://doi.org/10.1016/j.physbeh.2006.02.013

Woda, A., Mishellany-Dutour, A., Batier, L., François, O., Meunier, J.-P., Reynaud, B., ... Peyron, M.-A. (2010a). Development and validation of a mastication simulator. Journal of Biomechanics, 43(9), 1667-1673. https://doi.org/10.1016/j.jbiomech.2010.03.002

Woda, A., Mishellany-Dutour, A., Batier, L., François, O., Meunier, J.-P., Reynaud, B., ... Peyron, M.-A. (2010b). Development and validation of a mastication simulator. Journal of Biomechanics, 43(9), 1667-1673. https://doi.org/10.1016/j.jbiomech.2010.03.002

Woda, A., Nicolas, E., Mishellany-Dutour, A., Hennequin, M., Mazille, M.-N., Veyrune, J.L., \& Peyron, M.-A. (2010). The masticatory normative indicator. Journal of Dental Research, 89(3), 281-285. https://doi.org/10.1177/0022034509357022

\section{Legends}

Figure1: Schematic representation of the $\mathrm{AM}^{2}$ artificial masticator with insert of an open view of the mastication chamber in which the fixed and mobile masticatory disks are shown. The whole apparatus is $130 \mathrm{~cm}$ long and $30 \mathrm{~cm}$ in height. The masticatory chamber $(19.5 \mathrm{x} 9.5$ $\mathrm{cm}$ ) is located in the continuation of the shaft holding the mobile masticatory disk. 
645 Figure 2: Example of $\mathrm{AM}^{2}$ programming for meat mastication. Mean particle size distribution

646

647

648

649

650

651

652

653

654

655

656

657

658

659

660

661

662

663

664

665

666

667

668

curves are expressed as cumulative weight percentages of particles passing through each sieve during manual sieving. The force generated for food compression during mastication depends on the stiffness of the spring which must be chosen as a function of food resistance. The curve obtained with the spring $3(18.2 \mathrm{~N} / \mathrm{mm}$ of spring stiffness; $\mathrm{n}=4)$ and 22 masticatory cycles gave the best fit with the mean in vivo curve $(n=8)$. Spring 3 with only 20 cycles gave a higher median value $(=d 50$, theoretical sieve letting pass $50 \%$ particle mass $)$, indicating a poorly prepared food bolus with larger particles $(n=4)$. Spring $4(23.5 \mathrm{~N} / \mathrm{mm}$ of spring stiffness) was harder and gave a lower $d 50$ value when used with 22 masticatory cycles, indicating excess in food bolus disruption $(n=4)$. For the sake of readability, standard deviations are not drawn.

Figure 3: Comparisons between mean particle size distribution curves of boluses obtained in vivo and in vitro from different food types. Piece of beef: cooked samples, $2 \mathrm{~cm}$ square and $1 \mathrm{~cm}$ thick. Minced beef: same cooked meat, molded in the same sample shape as non-minced meat. Frankfurt sausage: cylindrical samples of $6.5 \mathrm{~g}$. Pasta products: cooked Fusilli pasta in $7 \mathrm{~g}$ bite. Coconut: $1 \mathrm{~cm}$ square and $1 \mathrm{~cm}$ thick sample. Gherkins: cylindrical sample of $3.5 \mathrm{~g}$. Each point represents the weight of the particles (in \%) retained in the corresponding sieve size added to the sum of all the preceding points (cumulative curve). The similarity required between in vivo and in vitro bolus granulometry was not limited to the median particle size (d50=50\% on cumulative curve) but sought for the whole mean particle size distribution curves. In these examples, better fitting could be obtained for minced meat and gherkins if further studies were carried out. For the sake of readability, standard deviations are not drawn.

Figure 4: Comparisons between mean particle size distribution curves for boluses obtained in vivo (A) and in vitro (B). The masticatory sequence of pork meat $(2 \mathrm{~cm}$ cubes) was interrupted 
669 after one, two, three and four quarters of the in vivo (A) and in vitro (B) chewing sequences $670(0.25,0.5,0.75$ and $1 ; n=10)$. In $\mathrm{C}$, particle size distributions were obtained for two types of 671 bread (white and whole wheat breads, sample $=1 / 4$ of a $2 \mathrm{~cm}$ thick slice cut in a French 672 baguette) after in vivo and in vitro mastication $(\mathrm{n}=10)$. The difference observed in vivo 673 between the two types of bread can be completely reproduced in vitro. For the sake of 674 readability, standard deviations are not drawn.

675 Figure 5. A: Evolution of four physical characteristics of bread boluses produced in vivo from 676 a French baguette after one, two or three thirds of the complete chewing sequence $(1 / 3,2 / 3$, 677 swallowing; $\mathrm{n}=10$ subjects $\mathrm{x} 2$ repetitions; sample $=1 / 0$ of a $2 \mathrm{~cm}$ thick slice). B: 678 Comparison of hardness and recoverability of pasta boluses produced in vivo and in vitro $(\mathrm{n}=$ 6795 subjects or replicates; cooked Fusilli pasta in $7 \mathrm{~g}$ bite). The food bolus was subjected to a 680 double compression test during a Texture Profile Analysis test (TPA) performed with an 681 Instron machine equipped with a flat piston head $(\varnothing 28 \mathrm{~mm})$ moved at a constant 682 displacement rate of $50 \mathrm{~mm} \cdot \mathrm{min}^{-1}$, a cylindrical container (int. $\varnothing 35 \mathrm{~mm}$, ext. $\emptyset 40 \mathrm{~mm}$ ) and a $683500 \mathrm{~N}$ load cell. The bolus was spread at the bottom of the cylindrical container and subjected 684 to $65 \%$ deformation of its initial height. In this example, hardness (N), adhesiveness (N.s), 685 elasticity and recoverability (both unitless) were extracted from the TPA curves (mean and 686 SD). Physical characteristics can be obtained in the same manner for in vitro boluses 687 produced with the masticator apparatus $\mathrm{AM}^{2}$.

688 Figure 6. A: Curve of a contaminant released in saliva along the mastication of a non689 alimentary product. The two curves were obtained for the same product containing two 690 different concentrations of the same toxic substance. B: Liquid content in a bolus of fruit (in $691 \%$ of bolus weight, mean and SD) after 24 in vivo masticatory cycles performed in normal 692 conditions and with the fruit sample placed in a bag while chewing to separate juice from 
693

694

695

696

697

698

699

700

701

702

703

704

705

706

707

708

709

710

711

712

713

714

715

saliva ( $\mathrm{n}=10$; mean and SD). C: Percentage of juice extracted from fruit after 15 and 24 in vitro masticatory cycles with $\mathrm{AM}^{2}(\mathrm{n}=10$, mean and $\mathrm{SD})$.

Figure 7. Chewing a non-alimentary gum. Cumulative loss of gum weight (A; in \%, mean and $\mathrm{SD})$ and cumulative concentration of glucose released in saliva (B; in g, mean and SD) were obtained from different time point measurements along 12 minutes of in vivo and in vitro mastication of the gum sample $(n=8)$.

Figure 8. Impact of food structure on free-iron and carotene release in saliva. A: Bolus of minced meat analyzed after normal mastication consisting of 10 cycles while the meat sample $(2 \times 2 \times 2 \mathrm{~cm})$ needed 32 masticatory cycles to produce swallowable boluses (mean and SD). B and C: At the end of mastication, free-iron release was greater for minced than for mouthful meat, both in the solid part of the bolus and in saliva. D: Examples of the oral release of carotene measured by HPLC in the salivary part of the bolus. For readability, spectra of betacarotenes determined in three saliva samples were superimposed according to the elution time on the x-axis. It clearly shows an increase of beta-carotene release in saliva with the progress of the masticatory sequence from the boluses collected at the beginning, in the middle of the masticatory sequence, and when the bolus was ready to be swallowed.

Figure 9. Production of maltose in the mouth during the artificial mastication of whole wheat and white bread samples, with the addition of water or saliva as the oral liquid ( $n=10$; mean and SD). All differences were significant.

Figure 10. A: Mean particle size distribution curve in the swallowable bolus after in vitro mastication of pasta and in the gastric compartment after in vitro gastric digestion. B: Kinetics of protein appearance in a simulated aged gastric compartment after normal and deficient mastication simulated with the $\mathrm{AM}^{2}(\mathrm{n}=3$; mean and $\mathrm{SD})$. Protein concentration was 
significantly lower $\left(^{*}\right)$ from 90 min digestion in deficient mastication compared to normal mastication.

Figure 11. Lipid and protein oxidation during in vitro mastication in the absence of saliva. A: Lipid oxidation during in vitro mastication without saliva, measured by malondialdehyde appearance (MDA) as thiobarbituric acid reactive substances (TBARS). B: Protein oxidation during in vitro mastication without saliva measured by the quantity of carbonyl groups (aldehydes and ketones present in the food bolus (reaction with dinitrophenylhydrazine (DNPH).

Figure 12. Effects of two levels of deficient force (Def Force $1 \& 2$ ) and motility (Def Motil 1 \& 2), and their combination, on the granulometry of poultry meatball boluses obtained with in vitro mastication ( $\mathrm{n}=10$; mean and $\mathrm{SD}) . d 50$ value (in $\mathrm{mm}$ ) is the median value of the particle size distribution in the food bolus and defined as the theoretical sieve size through which $50 \%$ of the mass can pass. Comparison was performed with normal mastication (NM). Significant differences against NM d50 values were observed from Def Force 2 condition. Data adapted from Peyron et al, 2018

Figure 13. Calibration (A) and measurement (B) of the resistance to compression of three gelatine products $(\varnothing 2 \mathrm{~cm}$; height $1 \mathrm{~cm})$ of different harnesses. Forces are measured with the strength sensor along the shaft actuating the mobile masticatory disk. A: the $\mathrm{AM}^{2}$ is activated with a pure translation movement, with an empty chamber and for five successive cycles. At the end of each cycle, the mobile (mandibular) jaw is stopped at initial contact, and contact for two seconds, without applying forces. Forces recorded in the translational axis with the strength sensor are in Newtons (N). The whole procedure lasted 23 seconds (s). The force sensor records four types of events: (1) friction of the mobile jaw against the mastication chamber wall while the jaw is moving towards the useful range of movements; (2) forces 
740 resulting from the air compressed by the progress of the mobile jaw in the chamber; (3) forces

741 resulting from negative air pressure while the jaw moves backwards; (4) null force while the

742 jaw is stopped for 2 seconds with no pressure against the fixed jaw. B: Measuring the force

743 during compression of three gelatines of different hardnesses. The events are the same as

744 those described above except for event 4 which displays the forces in Newtons (N) applied

745 during the mastication of the three gelatines differing in hardness. The translational

746 movement was performed at $100 \mathrm{~mm} / \mathrm{s}$.

747 Figure 14. Forces recorded with the strength sensor of the $\mathrm{AM}^{2}$ (Fig. 1) while chewing banana 748 samples with $1.8 \mathrm{ml}$ saliva, at $100 \mathrm{~mm} / \mathrm{s}$ translational speed. A: Successive bites performed in 7492 minutes chewing. The progressively decreasing force-from $25.42 \pm 0.81 \mathrm{~N}$ to almost zero, is 750 highlighted by black circles and illustrates that the banana sample was progressively crushed 751 and less resistant with the successive bites. B: Measures with an Instron machine performing 752 a single compression test in replicates on 2 banana samples $(2 \mathrm{~cm}$ diameter, $1 \mathrm{~cm}$ high) with a 753 cylindrical piston head of $2.8 \mathrm{~cm}$ diameter. The values of forces in Newtons $(26.99 \pm 1.08 \mathrm{~N})$ 754 were similar to the value obtained during the first bite with $\mathrm{AM}^{2}(25.42 \pm 0.81 \mathrm{~N})$. C and D: 755 Measures of forces developed during a five-bite compression to test the effect of banana 756 ripening on sample resistance with the $\mathrm{AM}^{2}$ mimicking a testing machine mode (no saliva, 757 spring of lowest stiffness, mobile disk actuated at $100 \mathrm{~mm} / \mathrm{s}$ ). 


\section{2. accent}

\section{PROOFREADING CERTIFICATE}

To whom it may concern,

the document bearing the title:

\section{ADDRESSING VARIOUS CHALLENGES RELATED TO FOOD BOLUS AND NUTRITION}

WITH THE AM ${ }^{2}$ MASTICATION SIMULATOR

was proofread and corrected by a native English speaker working for Accent Europe on 13 June 2019.

Articles proofread or translated by Accent Europe have been published in the following journals:

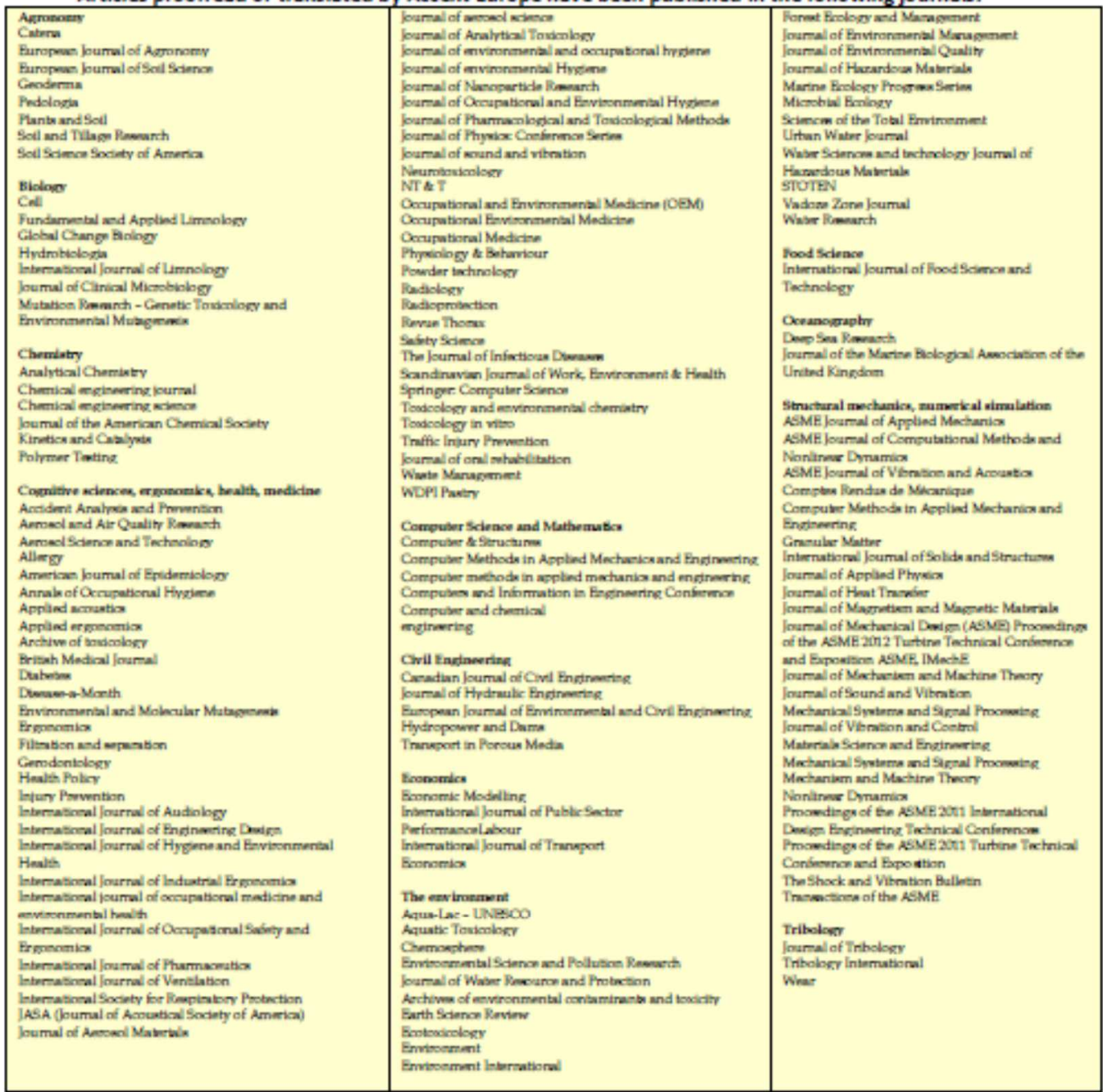

ACCENT EUROPE EURL - 3, rue Joseph RImaud 69130 ECULLY - Tel. : 0478330275 - Fax : 0478335048 e-mall : accent europe $g$ orange.fr - site web : http:-3/ww. accent-europe.fr euri d'un capltal de 30000 - $n^{2}$ siret 41384377200018 - code APE 921 B $N^{*}$ TVA intracommunautaire : FRO441384377200026 


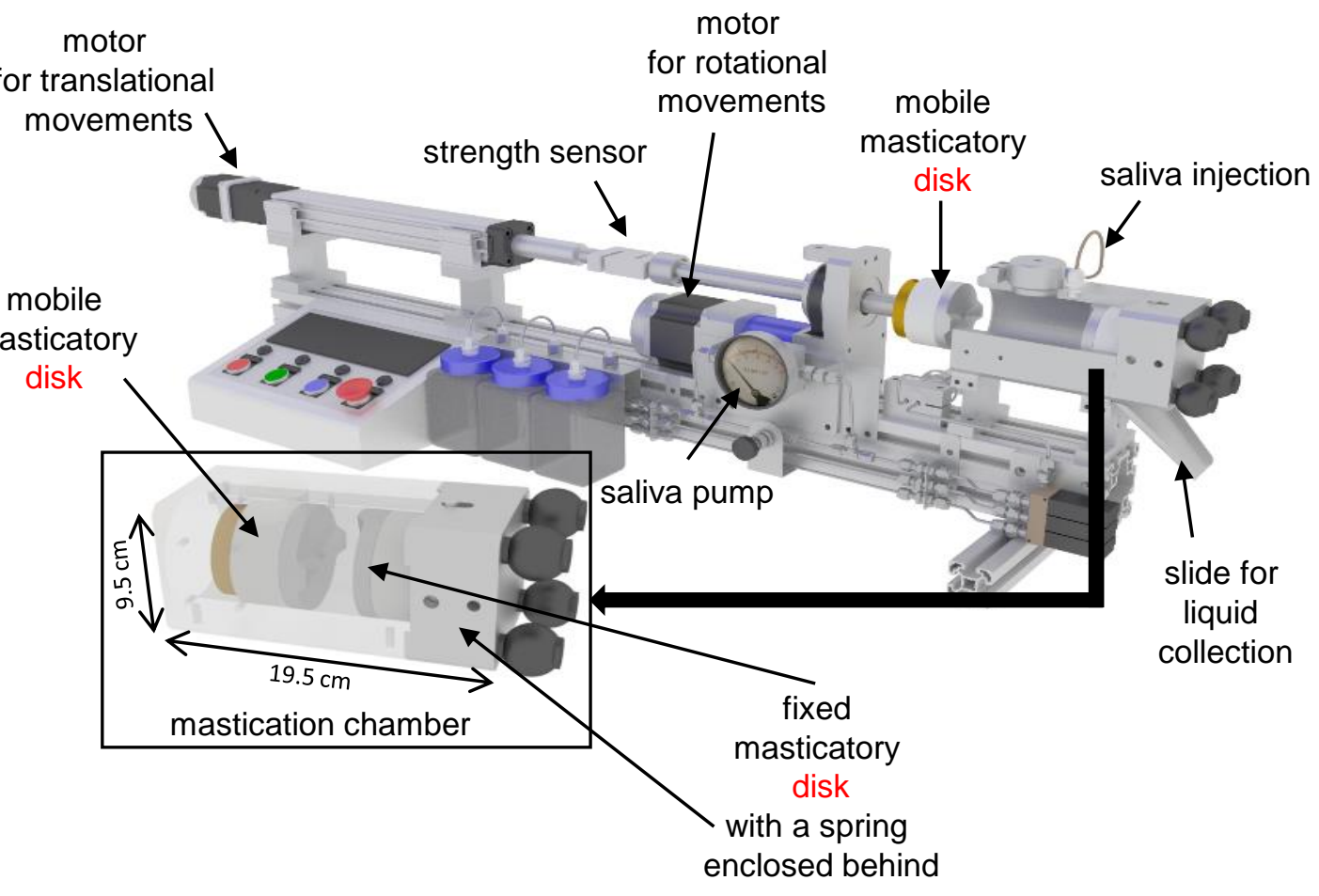

Figure 1 


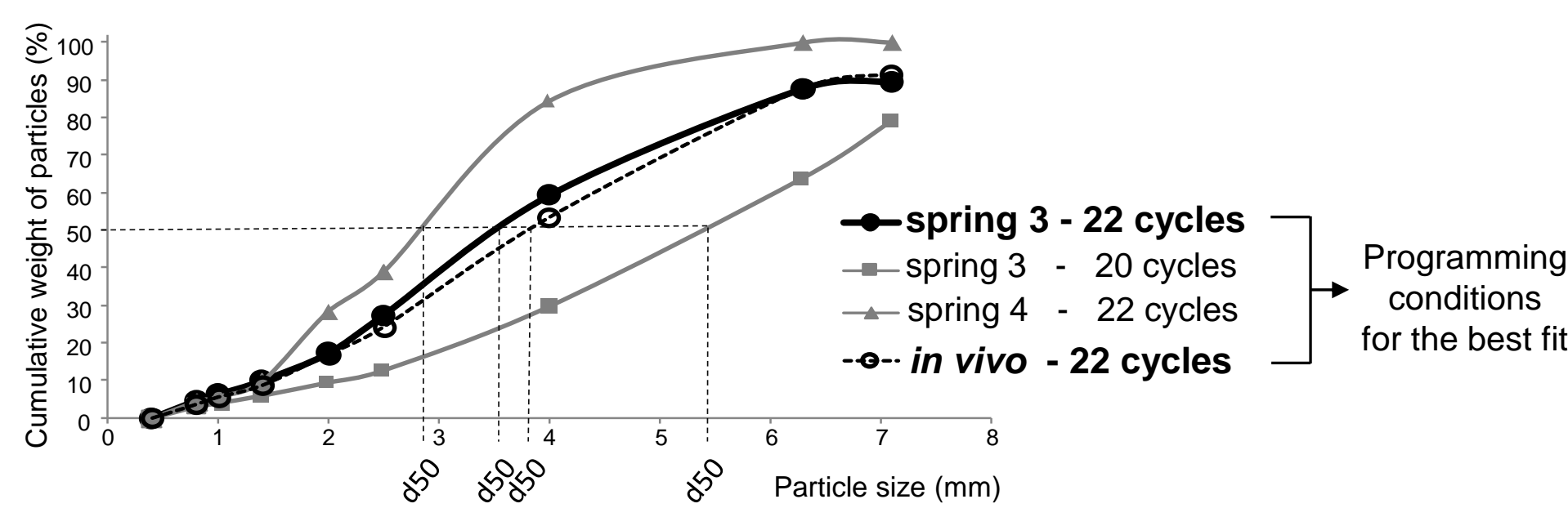

Figure 2 

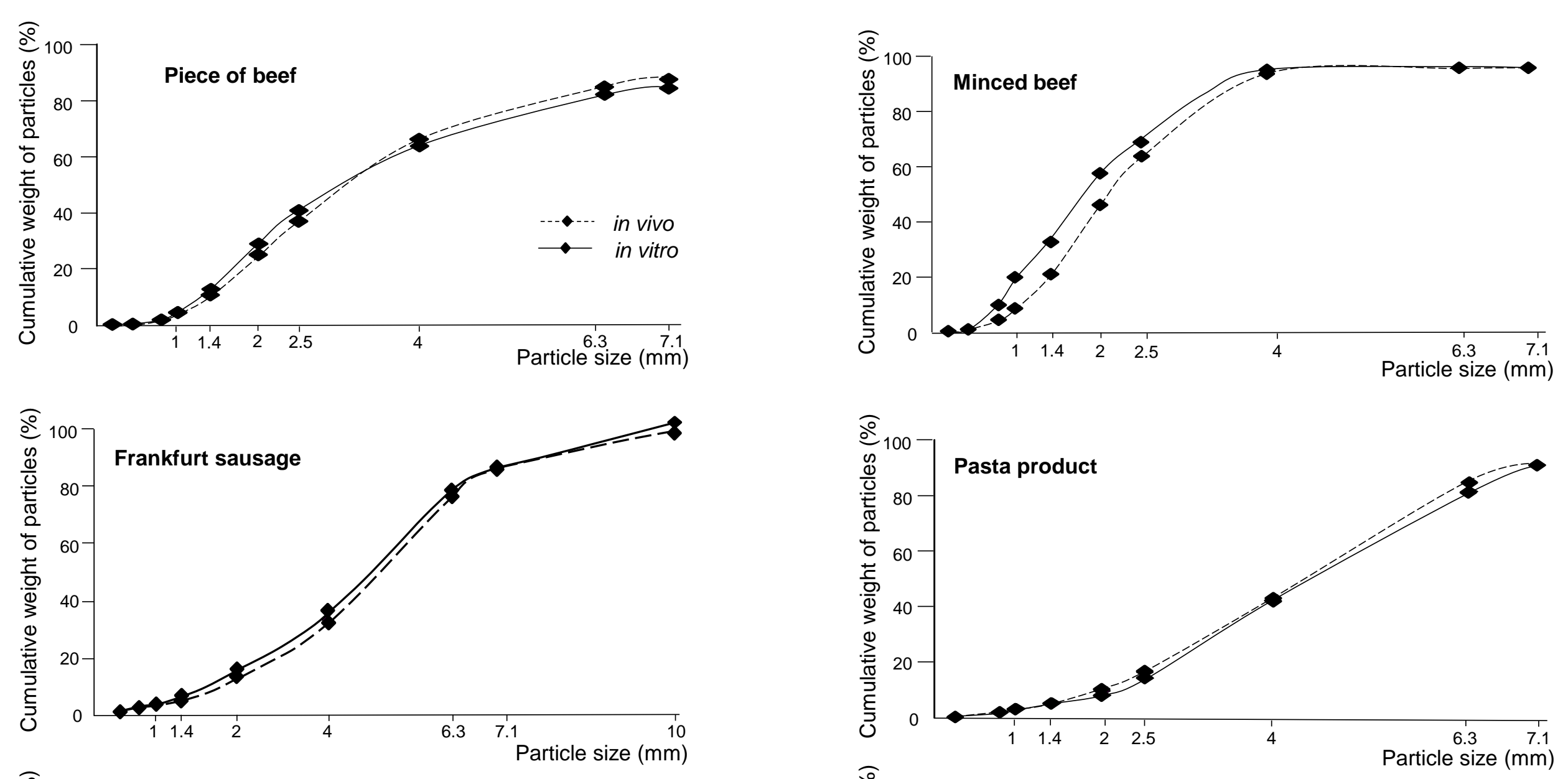

Figure 3
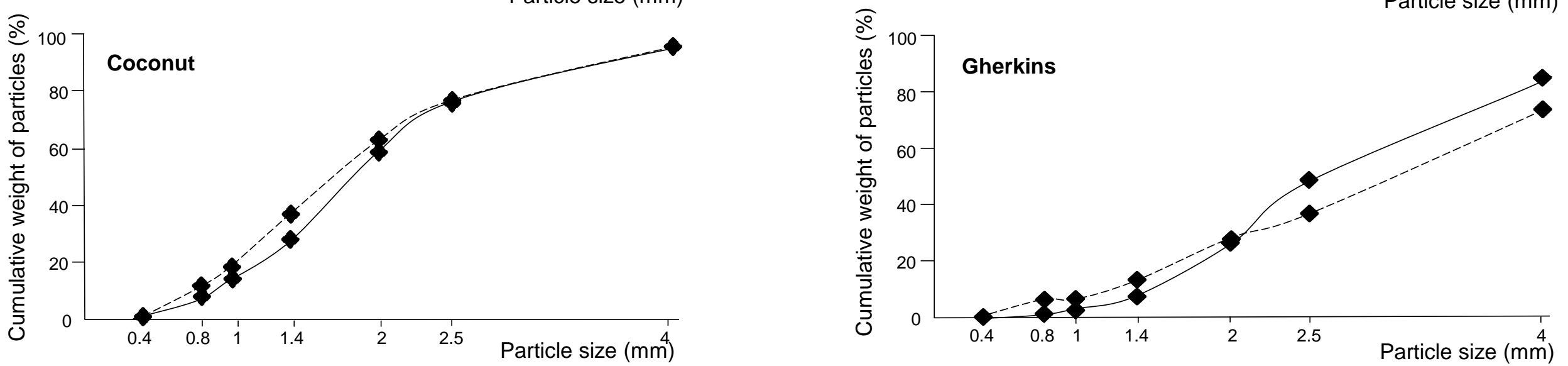
A

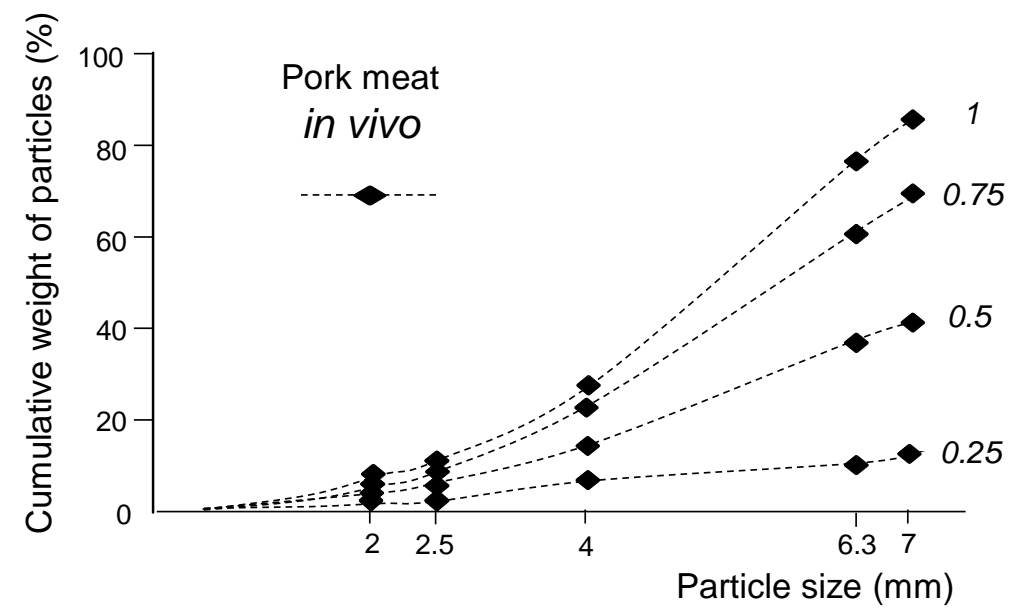

B

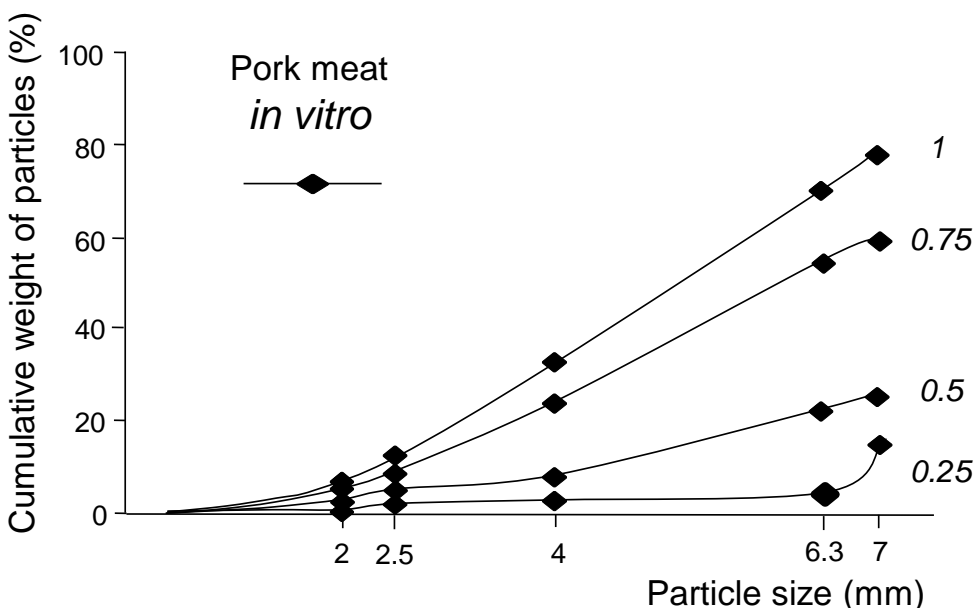

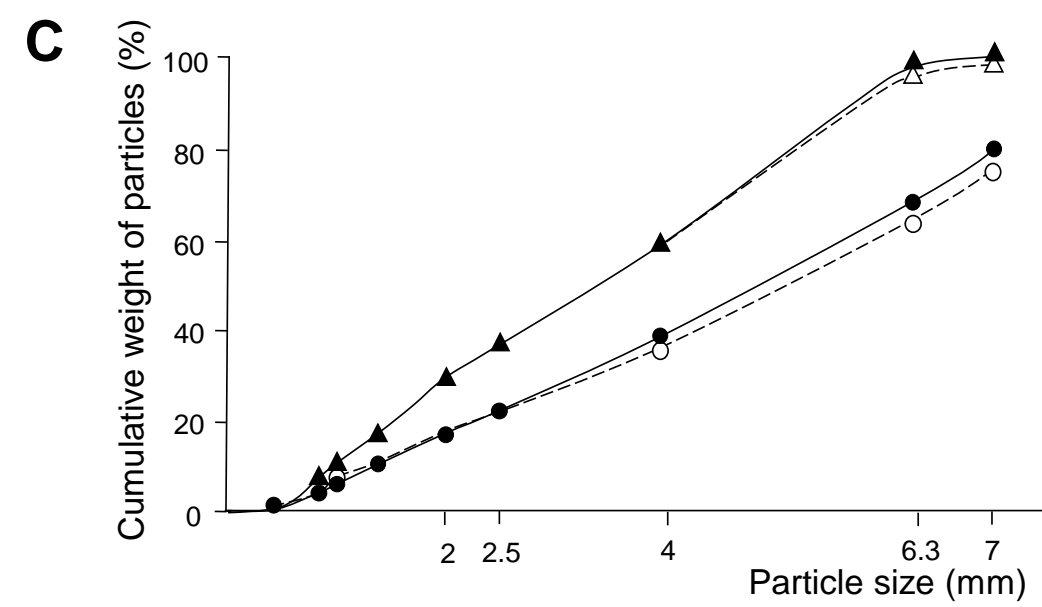

Whole wheat bread in vitro

Whole wheat bread in vivo

White bread in vitro

White bread in vivo

Figure 4 

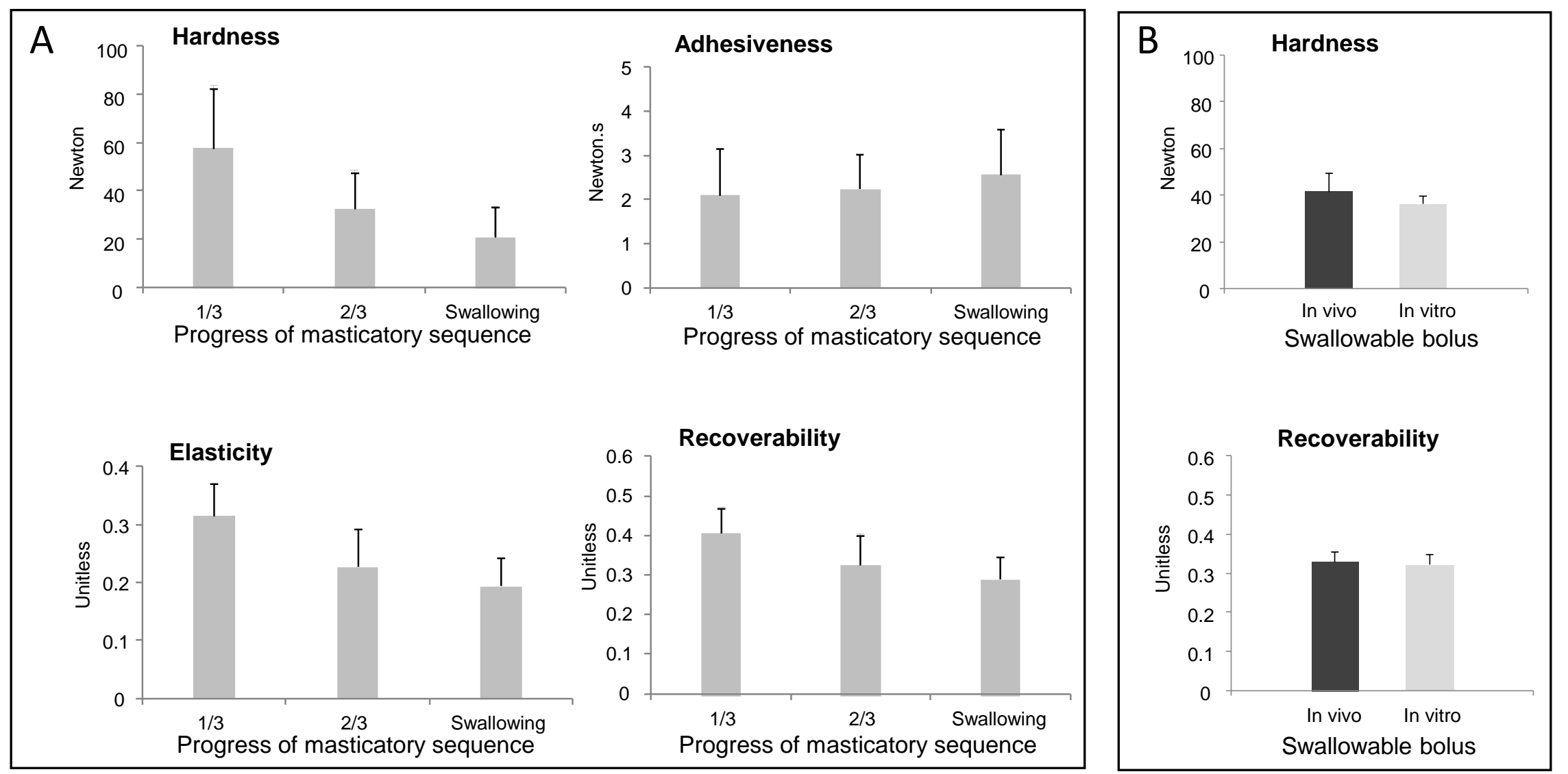

Figure 5 

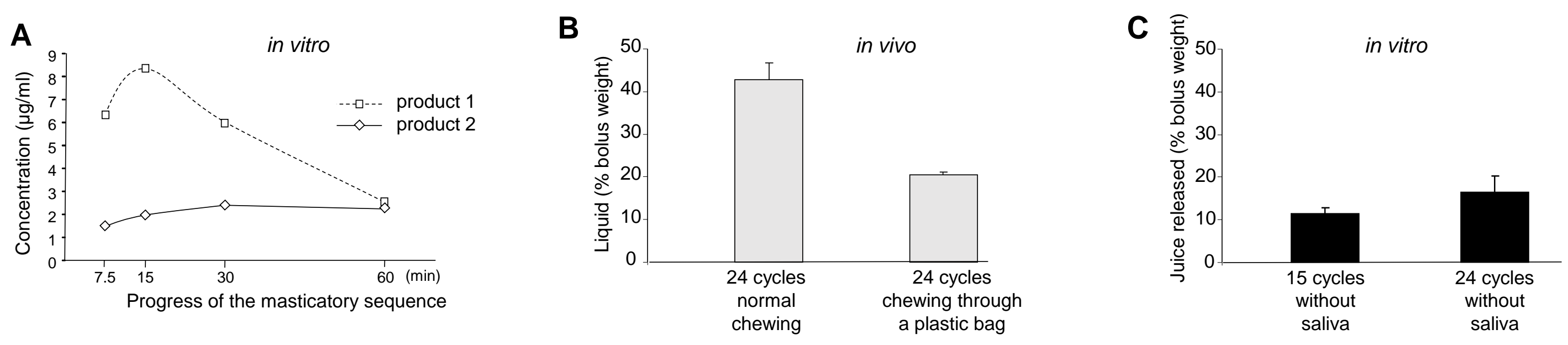

Figure 6 

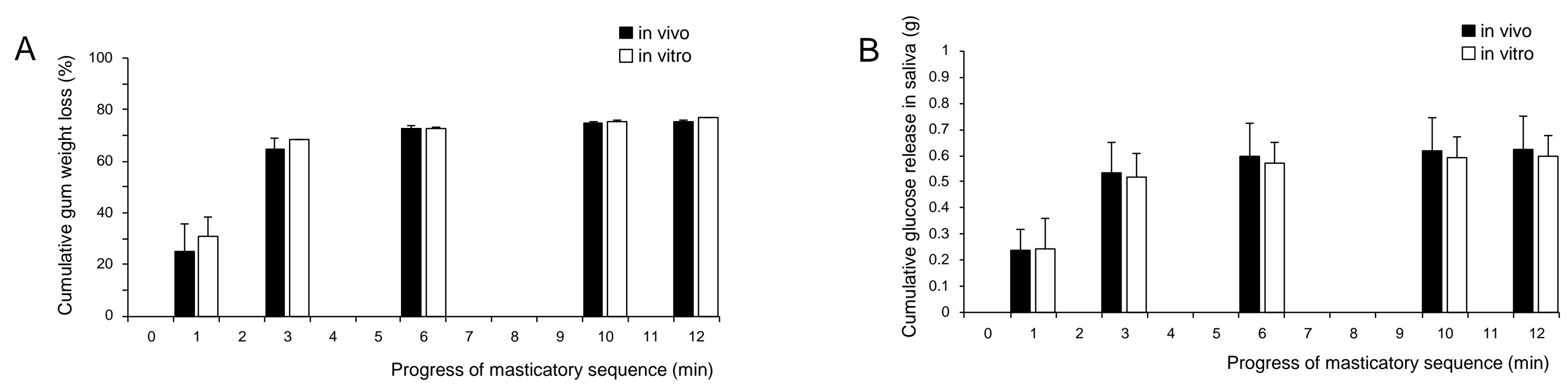

Figure 7 

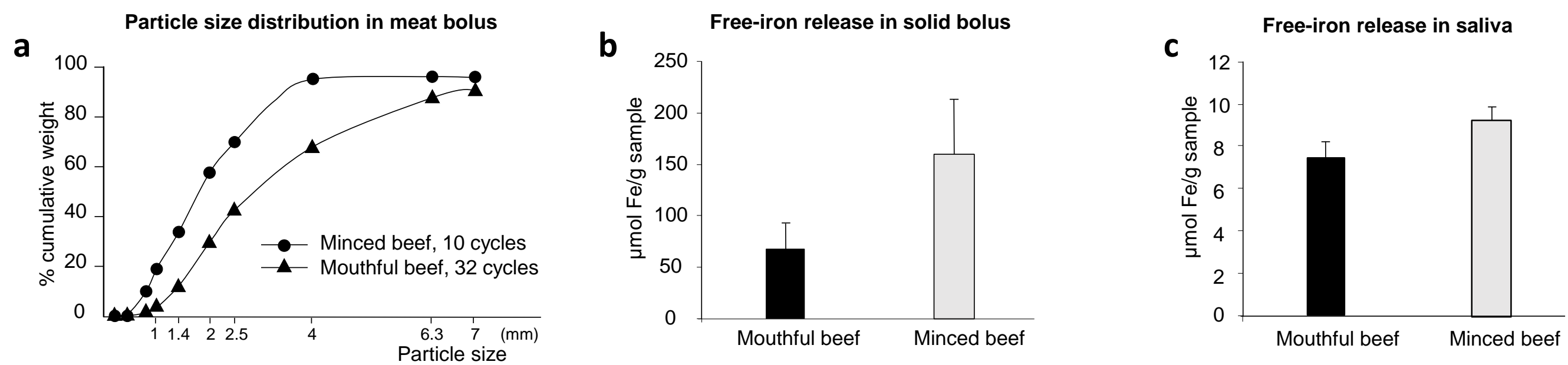

d

Figure 8

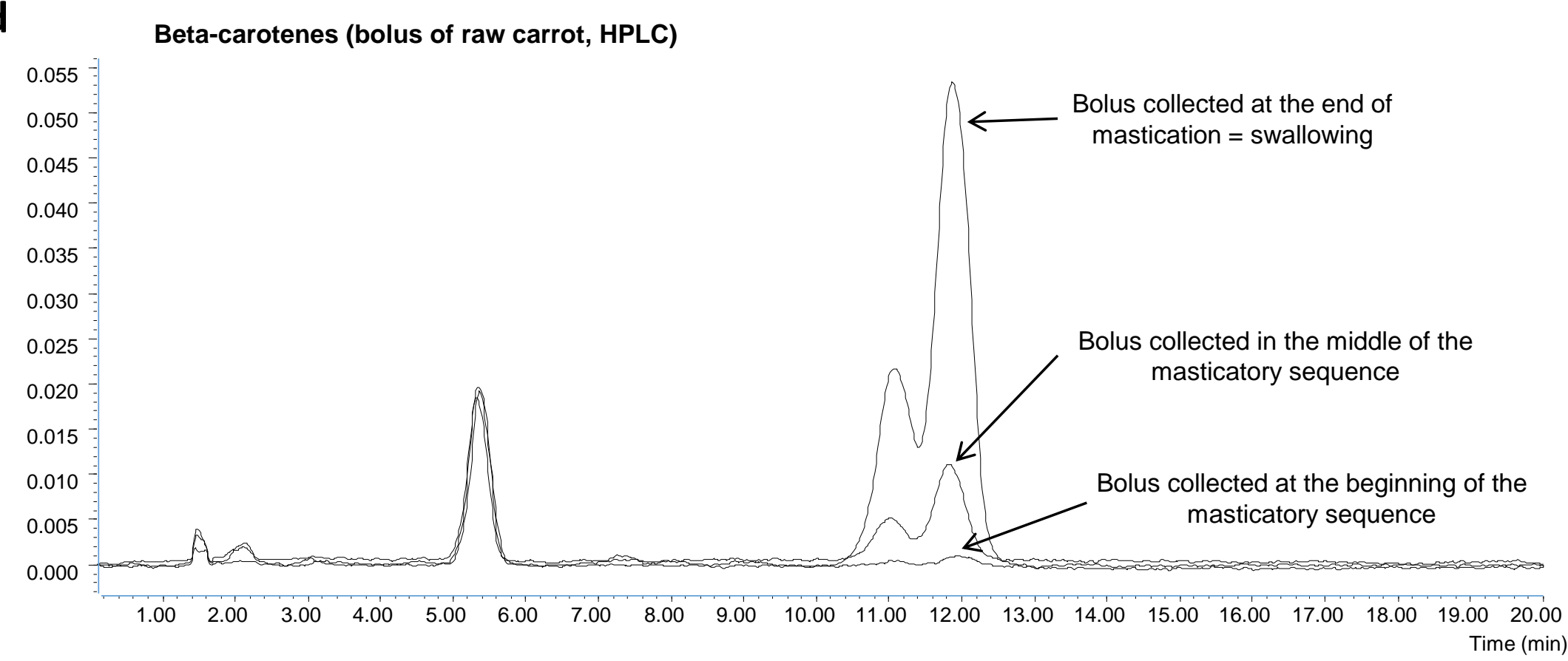




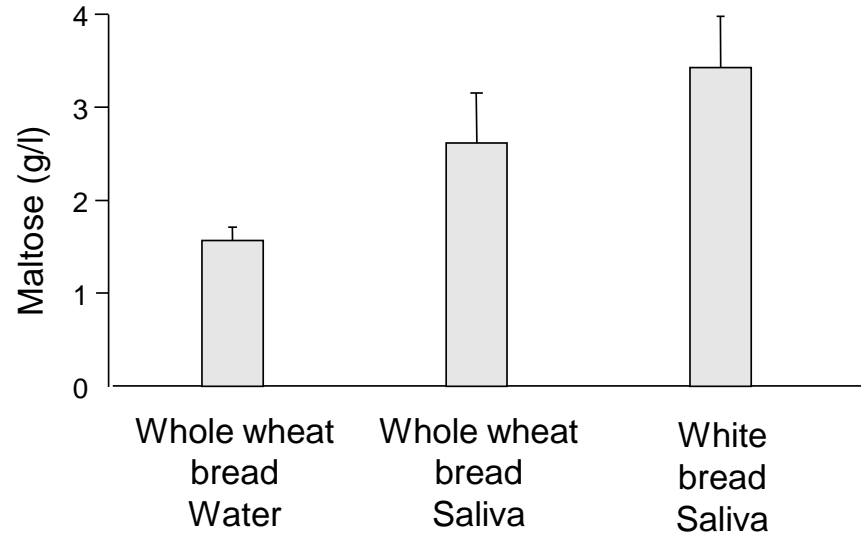

Figure 9 
A

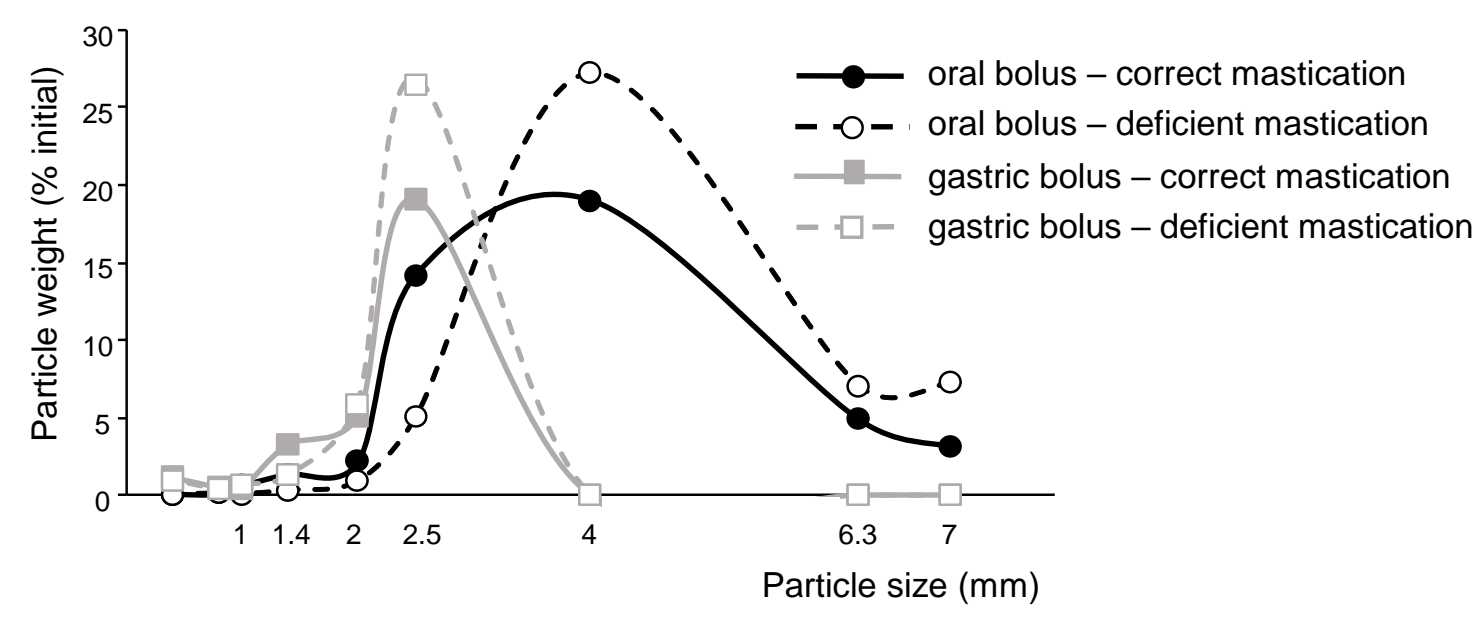

B

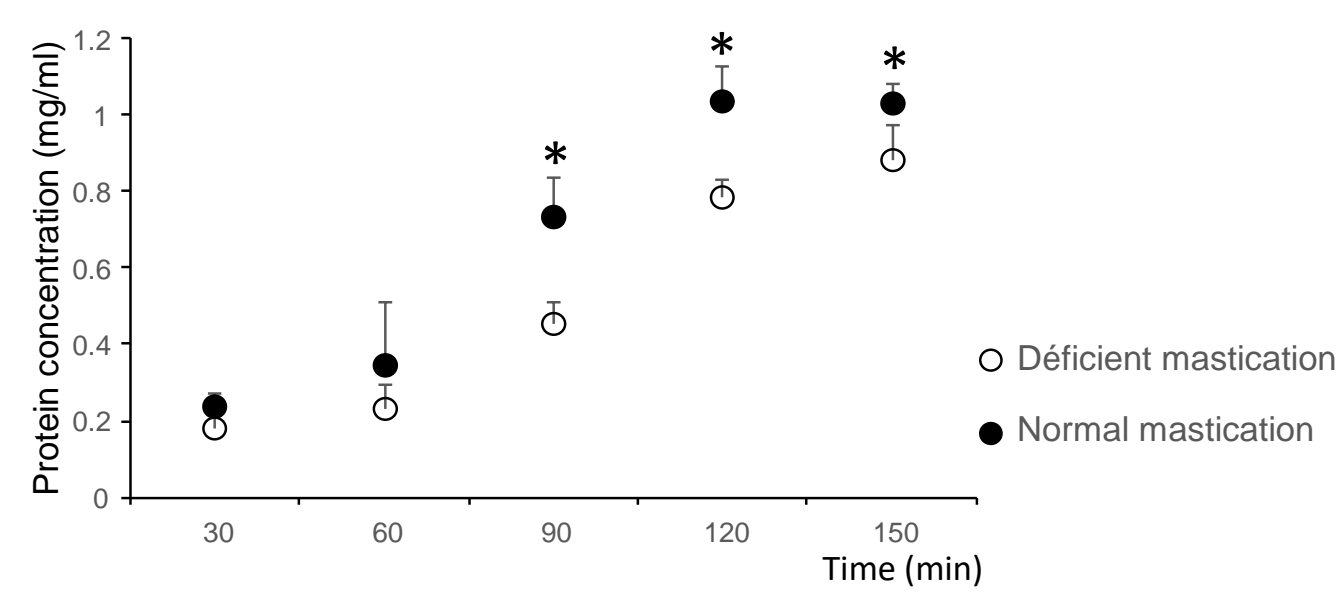

\section{Figure 10}


A

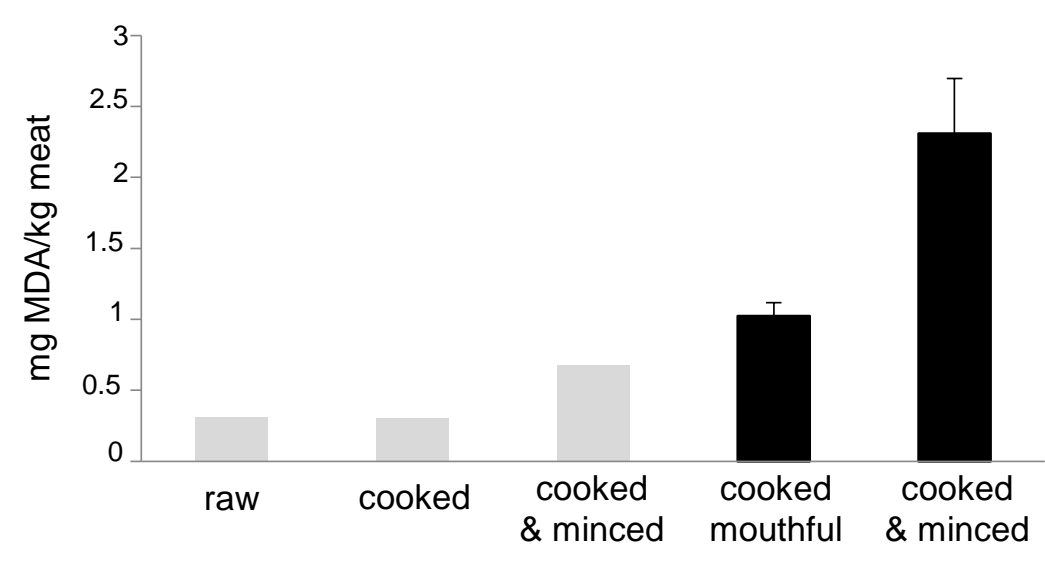

B

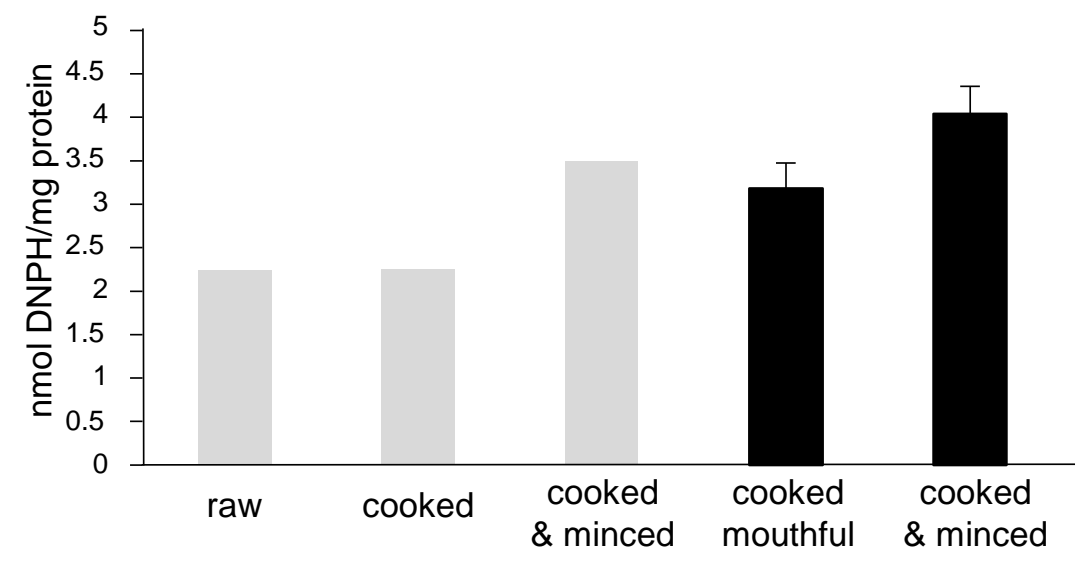

Food before chewing

Bolus before swallowing

Figure 11 


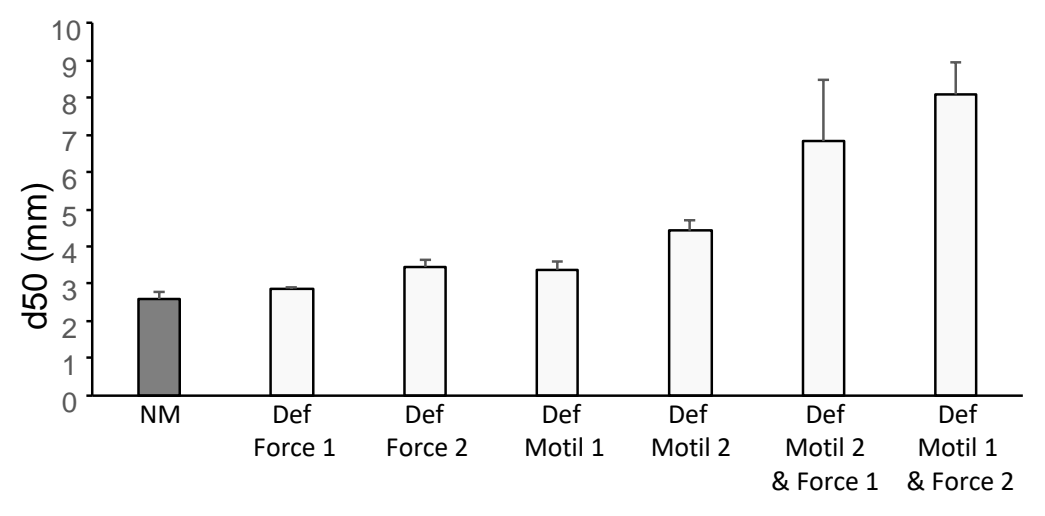

Figure 12 


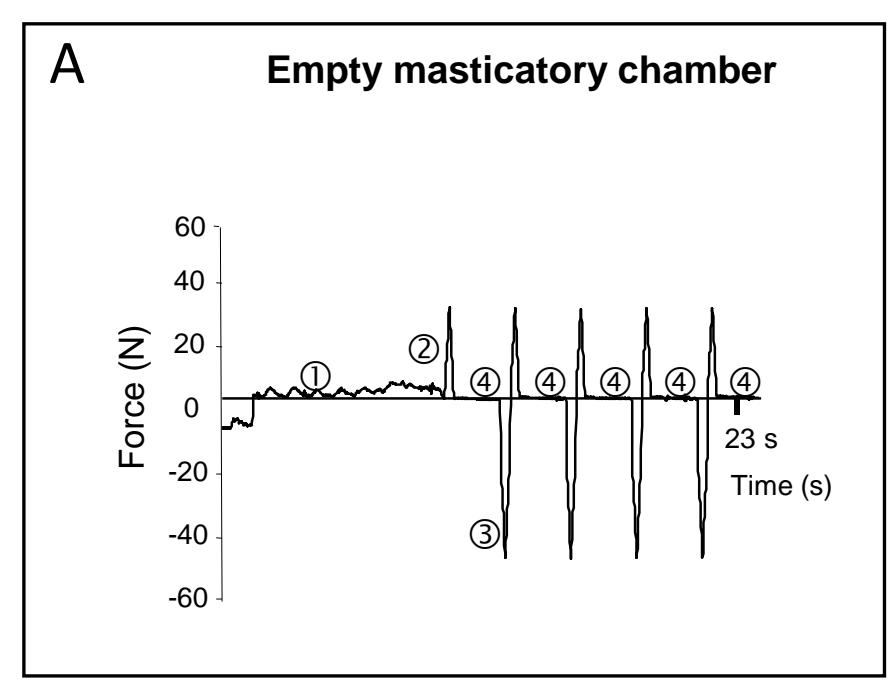

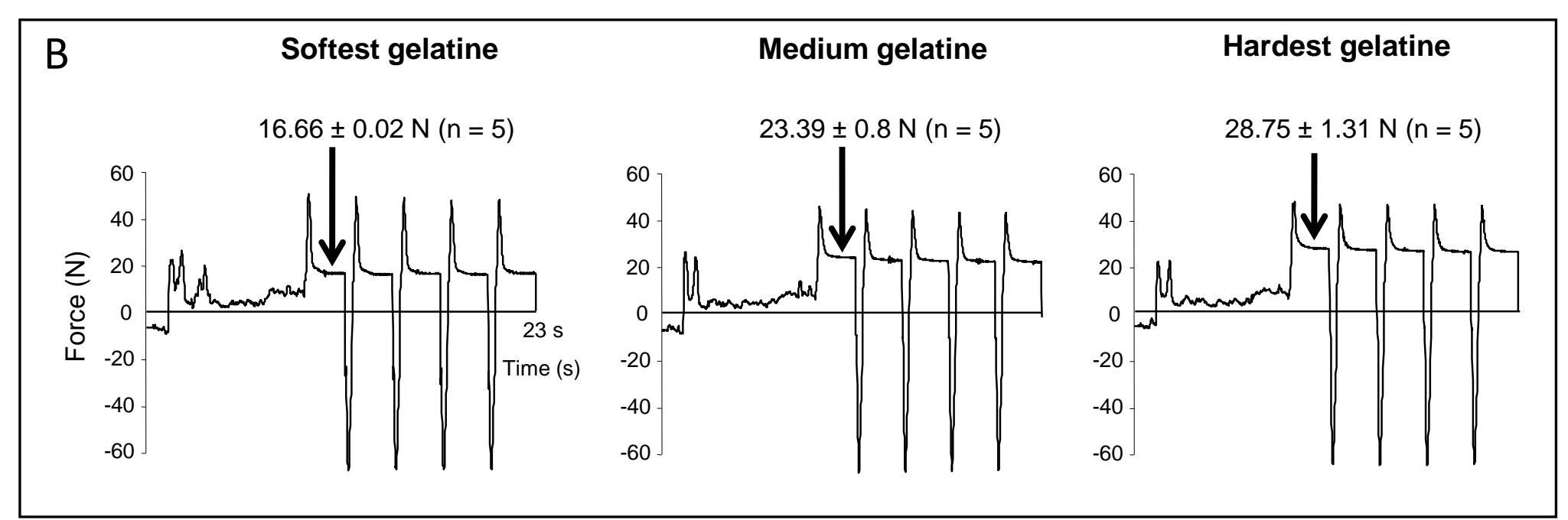

Figure 13 
Chewing of banana sample in $\mathrm{AM}^{2}$ in 36 cycles

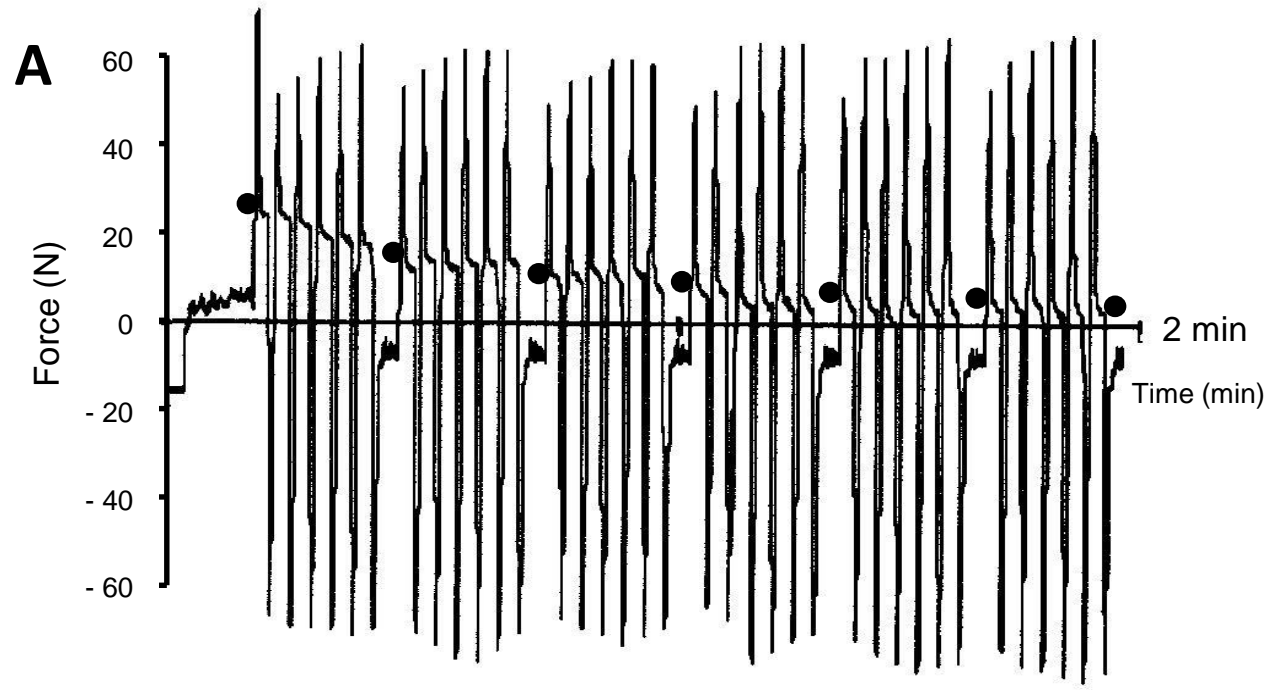

B Instron: compression test; 2 banana samples

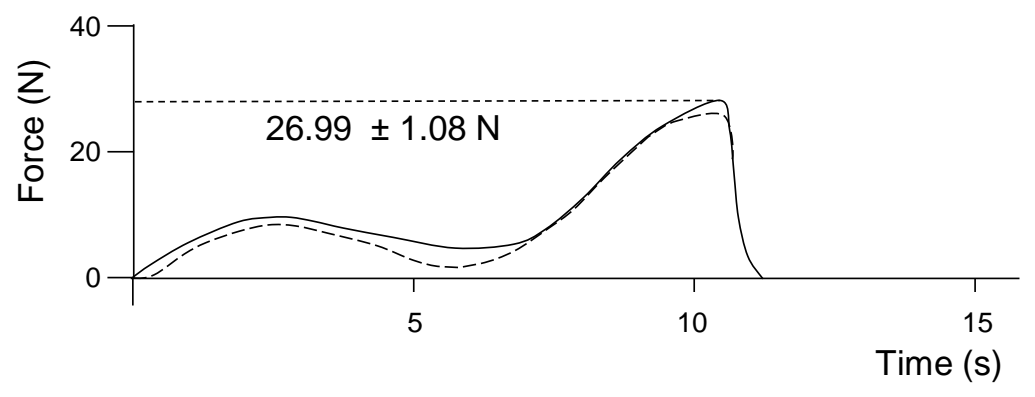

Five-bite compression of ripe and firm bananas samples in $\mathrm{AM}^{2}$
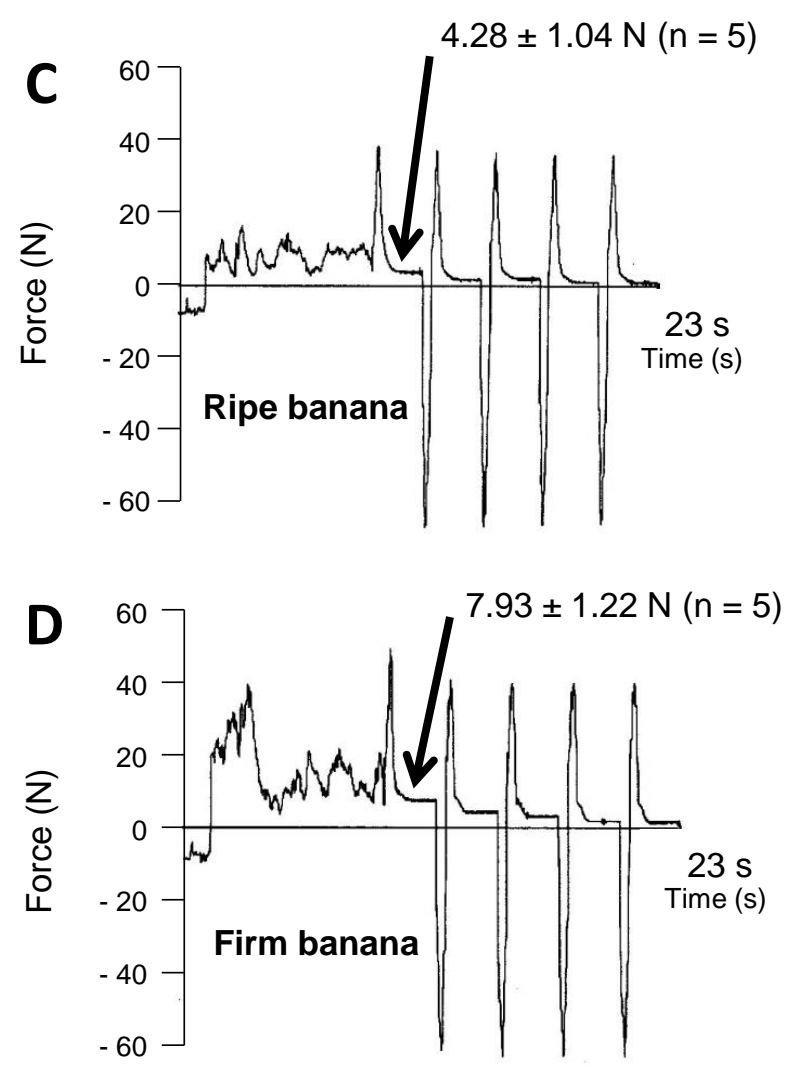

Figure 14 
in vivo

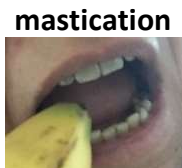

1

programming programming against in vivo food bolus
$\mathrm{AM}^{2}$

masticator apparatus

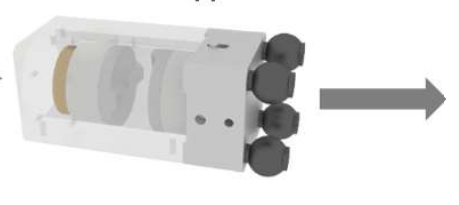

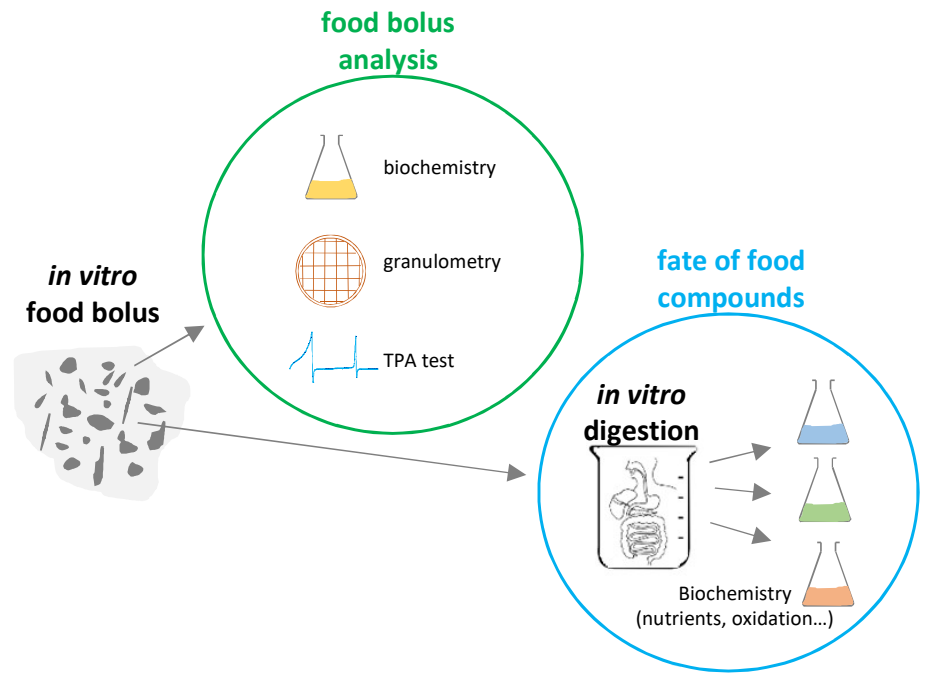

